Article

\title{
Agro-Livestock Farming System Sustainability during the COVID-19 Era: A Cross-Sectional Study on the Role of Information and Communication Technologies
}

\author{
Nesrein M. Hashem ${ }^{1, * \mathbb{D}}$, Eman M. Hassanein ${ }^{1} \mathbb{D}$, Jean-François Hocquette ${ }^{2}$, Antonio Gonzalez-Bulnes ${ }^{3, * \mathbb{D}}$, \\ Fayrouz A. Ahmed ${ }^{4}$, Youssef A. Attia ${ }^{5}$ and Khalid A. Asiry ${ }^{5}$ \\ 1 Department of Animal and Fish Production, Faculty of Agriculture (El-Shatby), Alexandria University, \\ Alexandria 21545, Egypt; em.mostafa@alexu.edu.eg \\ 2 INRAE, Clermont Université, VetAgro Sup, UMR1213 Herbivores, 63122 Saint-Genès Champanelle, France; \\ jean-francois.hocquette@inrae.fr \\ 3 Departamento de Produccion y Sanidad Animal, Facultad de Veterinaria, Universidad Cardenal \\ Herrera-CEU, CEU Universities, C/Tirant lo Blanc, 7, Alfara del Patriarca, 46115 Valencia, Spain \\ 4 Department of Economics and Agricultural Extension and Rural Development, Faculty of Agriculture, \\ Damanhour University, Damnhour 22516, Egypt; dr.fayrouz@agr.dmu.edu.eg \\ 5 Agriculture Department, Faculty of Environmental Sciences, King Abdulaziz University, \\ Jeddah 21589, Saudi Arabia; yaattia@kau.edu.sa (Y.A.A.); prof_1974@hotmail.com (K.A.A.) \\ * Correspondence: nesreen.hashem@alexu.edu.eg (N.M.H.); antonio.gonzalezbulnes@uchceu.es (A.G.-B.)
}

Citation: Hashem, N.M.; Hassanein, E.M.; Hocquette, J.-F.; Gonzalez-Bulnes, A.; Ahmed, F.A.; Attia, Y.A.; Asiry, K.A. Agro-Livestock Farming System Sustainability during the COVID-19 Era: A Cross-Sectional Study on the Role of Information and Communication Technologies. Sustainability 2021, 13, 6521. https:// doi.org/10.3390/su13126521

Academic Editors: George Saridakis and Nikolaos Dadios

Received: 26 April 2021

Accepted: 2 June 2021

Published: 8 June 2021

Publisher's Note: MDPI stays neutral with regard to jurisdictional claims in published maps and institutional affiliations.

Copyright: (c) 2021 by the authors. Licensee MDPI, Basel, Switzerland. This article is an open access article distributed under the terms and conditions of the Creative Commons Attribution (CC BY) license (https:// creativecommons.org/licenses/by/ $4.0 /)$.

\begin{abstract}
In the near future, the year 2050, agricultural production should expand to fulfill the needs of approximately 9.7 billion inhabitants. Such an objective should be harmonized with social, economic, and environmental sustainability aspects to maintain safe food production and food security worldwide. For more than a year, the COVID-19 pandemic has raised and is still strongly disrupting the agro-livestock production sector, similar to several other economic sectors. In this sector, the relationships between suppliers, producers, and consumers should always continue to maintain the activity of the production chain, which are impaired by social distancing decisions taken following the emergence of the COVID-19 pandemic. In this study, a global cross-sectional survey (translated into four languages: Arabic, English, French, and Spanish) was shared with people belonging to the agricultural sector to identify: (1) the role of the agricultural information and communication technologies (ICTs) in agro-livestock farming systems sustainability during the period of COVID-19 pandemic, (2) the need for such technologies in the agricultural sector, and (3) the factors that affect the use of such technologies. The results showed that the most frequently used agricultural ICTs were social media (Facebook and/or WhatsApp; $27.3 \%$ ) and online platforms and Internet services (26.3\%), whereas robotic vehicles and/or drones $(6.6 \%)$ were less frequently used. During the emergence of the pandemic, the major reasons impacting agro-livestock farming systems' sustainability were social distancing (30.0\%), shortage of labor (17.7\%), maintaining precision farm management $(14.8 \%)$, product marketing $(14.2 \%)$, access production inputs $(7.2 \%)$, and others $(16.1 \%)$. Applying agricultural ICTs solved many obstacles related to the production process, such as maintaining precision farm management $(25.6 \%)$, product marketing $(23.6 \%)$, and access production inputs (16.1\%). The subgroup analyses of the results considering the degree of country advancement, size of agribusinesses, and role/position of respondents in the farm highlighted the importance of supporting the use, availability, and awareness of agricultural ICTs at least for some groups of people such as those belong to developing countries, laborers, and small-scale agri-business holders. This cross-sectional study highlights the urgent need to turn to and to expand the use of new agricultural ICTs to meet the growing demand for food production in the world and to ensure the resilience and sustainability of farming systems, specifically under unexpected and extreme conditions.
\end{abstract}

Keywords: SARS-CoV-2; agriculture; farming systems; information communications technology 


\section{Introduction}

Globally, the agricultural sector (crop and livestock production) accounts for approximately one-third of the total gross domestic product [1]. In addition, agriculture is the main source of income for farmers in most developing countries. Moreover, it provides human food and raw materials for many industries and contributes to environmental ecology. Approximately $60 \%$ of the world's population depends on agriculture for survival [2]. Recent statistics announced by the Food and Agriculture Organization (FAO) and United Nations revealed that the pressure on the agricultural sector is increasingly growing, as the current world population ( 7.3 billion people) is expected to increase by approximately $33 \%$ and to reach 9.7 billion by 2050 [3], with around 113 million people suffering acute severe food insecurity [4]. Furthermore, agriculture can play a role in zoonotic disease epidemiology by changing land use (deforestation) and biodiversity. For example, intensive livestock production systems, which encompass large numbers of animals with low genetic diversity, may amplify pathogens and provide them with an opportunity to mutate and become transmissible to humans $[4,5]$. The emergence of the ongoing coronavirus disease 2019 (COVID-19) pandemic caused by the novel severe acute respiratory syndrome coronavirus 2 (SARS-CoV-2) and its concomitant difficulties in production and trading management has worsened the challenges faced by the agricultural sector, compromising the sustainability of the agricultural sector and exposing the workers in this sector to lose their livelihood source.

In the era of the COVID-19 pandemic, many restrictive actions have been taken to control the outbreak, mainly movement restrictions [6], which drastically affect the continuity of agricultural activities and related agri-food businesses [7-9]. Lockdowns and curfews prevent farmers from applying regular and precision farming systems/management, accessing production inputs, marketing agricultural/livestock products, and communicating with professionals to obtain appropriate extensions and advice, including shortage of labor/staff $[8,10]$.

In this scenario, the digitalization of agriculture, which refers to tools for digitally collecting, processing, storage, retrieval, and managing and sharing electronic data/information along the agricultural value chain in multiple formats [11,12], may present an efficient solution for the ongoing production obstacles. There is currently a revolution in the agricultural information and communication technologies (ICTs), as many vehicles such as robotic vehicles and drones, computers, radio, internet services, social media, and mobile applications have been developing.

The agricultural sector has passed through several revolutionary stages. Around 12,000 years ago, the first agricultural revolution occurred when humans started farming. The second agricultural revolution was related to the end of feudalism in Europe in the 17th century, while the third agricultural revolution, the green revolution, occurred between the 1950s and 1960s and was related to the introduction of chemical fertilizers, pesticides, highyield crops, and heavy machinery. In the 21st century, the fourth agricultural revolution, a 'digital agricultural revolution', emerged and was related to the emergence of digital technologies and artificial intelligence [13]. In 2019, the FAO [14] focused on the importance of the newest agricultural revolution based on ICTs as a powerful tool to ensure that agriculture meets the needs of the global population in the future.

Currently, the market size of agricultural ICTs is constantly growing through different farming systems and levels in both developed and developing countries [15]. As an example, the global smart agriculture market size (investments in agricultural technologies) is projected to increase threefold by 2025 , reaching $\$ 15.3$ billion (compared to being slightly over $\$ 5$ billion back in 2016 [16]). Based on geographic distribution, the global smart agriculture market size is dominated by North America (the United States, Canada, and Mexico), Europe (Germany, the United Kingdom, France, and Italy), the Asian-Pacific region (China, India, and Japan), Latin America, and Middle East Africa. Among these regions, North America accounted for the largest share of the global smart agriculture market in 2017 owing to the growing need to improve agricultural productivity [17]. The smart 
agriculture market is dominated by a few globally established players belonging mainly to developed countries such as the United States (Deere \& Company, Trimble, Topcon Positioning Systems, and Raven Industries), Sweden (DeLaval), and France (Antelliq) [18].

This positive dynamic in the agricultural ICTs' market size could be ascribed to the fact that agricultural ICTs are not only important tools for smart farming and/or precision agriculture, but also for strengthening the communications between the governments, business owners, consumers, professionals/consultants, and farmers. These integrations between the parties concerned could help to increase the overall food production and to boost food security through improving the resilience of the agricultural value chain [19].

Reports and studies conducted during the era of the COVID-19 pandemic have suggested that the emergence of the pandemic significantly contributed to reshaping the manner of social communication around the world, emphasizing the necessity of broadening the digital revolution tools in different farming systems and agricultural value chains $[20,21]$. The size of the global digital agriculture market is projected to grow from $\$ 5.6$ billion in 2020 to $\$ 6.2$ billion by 2021, which corresponds to a compound annual growth rate of $9.9 \%$ due to the effects of the COVID-19 pandemic [22]. However, whether farmers and associated stakeholders are keen to implement agricultural ICTs to maintain farming system sustainability is unknown. Therefore, the aim of the current global cross-sectional study is to identify the perceptions of farmers and stakeholders toward the role of ICTs in farming systems' sustainability during the period of COVID-19 pandemic, and if the pandemic affects the development and the need for such technologies in the agricultural sector. Indeed, factors that affect the use of such technologies such as the attitude and awareness of individuals and the availability of such technologies for who are involved in agro-livestock farming systems were considered. Therefore, this study is the first one directly asking farmers and associated stakeholders worldwide for their perceptions of the agricultural ICTs benefits during the COVID-19 sanitary crisis and the actions should be taken to empower the role of these technologies in agro-livestock farming systems. The structure of this article is made in the following pattern. Section 2 presents the literature findings about the factors affecting agricultural ICTs use and the role of agricultural ICTs in maintaining the resilience of agro-livestock farming systems as well as the methodology and conceptual framework of the study. Section 3 presents the results of this study in detail. Section 4 consists of discussions, and Section 5 presents the main implications and limitations of the study and directions for future research.

\section{Materials and Methods}

\subsection{Hypotheses Based on Literature Review}

2.1.1. Agricultural Information and Communication Technologies (ICTs): Knowledge, Availability, and Affordability

The real application of agricultural ICTs requires sufficient awareness of agricultural ICT handling and utilization skills, which must be assessed. In addition, the readiness and affordability of well-designed digital infrastructure are crucial requirements for encouraging the use of ICTs by all the users involved in the agricultural sector. The inadequacy of any of these requirements can easily interrupt the contribution of agricultural ICTs to beneficiaries [23]. These aspects may need hard efforts and certain improvements, specifically in developing countries, small-scale holders, and users who are likely to suffer from digital ignorance. For example, a wide gap exists between developed and developing countries in terms of the availability and acceptability of cellular network technology, 3G and 4G cellular coverage, which hampers telecommunications efficacy, specifically in marginalized areas, such as rural areas. Similarly, the accessibility and affordability of digital devices may present another obstacle. According to a Global System for Mobile Communications report in 2016, among the 750 million-plus farmers in the 69 surveyed countries, only approximately $39.3 \%$ (295 million) had mobile phones [24]. The largest gap in agricultural ICT adoption is for medium and small farms in developing countries that do not use 
motorized mechanization (engine-driven equipment, such as tractors, planters, seeders, harvesters, fertilizer applicators, sprayers, and automatic milking systems) [25].

Despite the existing barriers to the use of agricultural ICTs, a growing body of evidence shows that the progress of agricultural ICT access is a key enabler of agricultural sector change. Several studies have shown the acceptability of farmers, specifically those belonging to developing countries and/or having small-scale agribusinesses, to transform into digital agriculture and the use of agricultural ICTs to improve their agribusiness outputs [26-28].

Identifying major obstacles that may hinder the use of agricultural ICTs may help to accelerate the use of such technologies, meeting the global change in communication patterns in other economic and social sectors [29]. Thus, one objective of this study is to check the hypothesis that a lack of knowledge, availability, or affordability can be a barrier to the implementation of agricultural ICTs.

Therefore, we worked on the first hypothesis regarding the importance of, on the one hand, detailed information provided by farmers/stakeholders about the recent available ICTs (mobile applications, online platforms, social media, robotic vehicles, and drones) that can be used as agricultural ICTs and, on the other hand, on obstacles (lack of knowledge, availability, and affordability) that may restrict the use of agricultural ICTs.

Hypothesis 1 (H1). Detailed information about the recent available agricultural ICTs for users engaged in the agricultural sector, specifically vulnerable groups, and obstacles that may restrict the use of agricultural ICTs are crucially required to encourage the use of agricultural ICTs on the ground.

\subsubsection{Role of Agricultural ICTs in Agro-Livestock Farming System Sustainability}

The provision of the digital agricultural revolution, including ICTs, big data analysis, and the Internet of things, can affect all parts of the agricultural value chain, including onfarm practices and off-farm segments, by improving communication among all agricultural value chain actors. This improvement can reduce the gap between farmers and information service providers or large value chain actors (traders, processors, and policy makers) [30,31] Furthermore, digital agricultural applications can confront challenges that face a growing demand for food, such as the scarcity of natural resources, climate change, and food waste, by making the agricultural production/value chains more equitable, efficient, and environmentally sustainable than before [32]. In this context, the use of precision agriculture technologies can increase crop and/or animal yields. For example, in US peanut farms, the use of soil maps is associated with a 13\% increase in peanut yield. Another study in Argentina revealed that a precision agriculture approach created using crop physiological principles resulted in a 54\% higher farm outputs [32]. Digital agriculture, mainly digital agricultural extension (E-extension), can also improve farmers' productivity by improving their skills and knowledge. E-extension services can provide farmers with decision-support services in easy and simple ways, such as mobile applications, SMS messages, videos, or other digital platforms. In this context, sugarcane farmers who receive specific agricultural advice via SMS messages had an $11.5 \%$ increase in sugarcane yield [33].

Due to the expected positive roles of agricultural ICTs in sustaining the resilience of agro-livestock farming systems under normal conditions, the use of agricultural ICTs during the COVID-19 pandemic era has been proposed as a solution for maintaining agrolivestock farming systems under the measures of physical distancing and lockdowns [34-36]. Farmers, specifically those belonging to vulnerable groups, suffer from accessing production inputs, markets, extension services, and other key services [8]. Thus, many organizations have launched different ICT-dependent programs to support farmers and producers. For example, the FAO has launched a specific platform called Technologies and Practices for Small Agricultural Producers, illustrating over 900 proven practices and technologies covering 22 aspects related to agro-livestock farming systems (livestock and crop production, fishery and aquaculture, forestry, agricultural mechanization, post-harvest and 
marketing, management of natural resources and climate change, food security, capacity development, and disaster risk reduction), which is available to a global audience [37].

Regardless of the ongoing studies and organizational reports that uphold the positive roles of agricultural ICTs in maintaining the resilience of the agro-livestock production chains [37-39], more reliable information is still needed from the beneficiaries themselves worldwide to evaluate the real impact of using agricultural ICTs during the normal conditions and/or during the pandemic on the outputs of their agribusinesses. That is, the perceptions and acceptance of agricultural ICTs by farmers and other stakeholders are key factors of success, which have never been studied in the context of the COVID-19 crisis. Furthermore, this study considered the COVID-19 pandemic as a sort of a social and economic shock, and then, globally assessed the impact of the pandemic on the resilience of the agro-livestock production chains, considering the socio-economic status of the respondents. From these novel resilience points of view, these evaluations may aid policy makers and researchers worldwide to discuss the capacity of agricultural ICTs for supporting agro-livestock production chains to cope with uncertainties related to public health and its resilience attributes, such as farmers' entrepreneurship and social networks.

According to a previous literature survey, a conceptual framework was designed (Figure 1) to obtain information about: (1) the awareness, handling, availability, and affordability of agricultural ICTs during normal circumstances and during the period of the COVID-19 emergence and (2) the efficacy of agricultural ICTs during the pandemic period to sustain the resilience of the agribusinesses. In addition, relationships among the degree of a country's development, size of agribusiness, and the role/position on the farm of respondents were introduced as independent variables to assess their effects on the dependent variables designed to assess the awareness, handling, and availability of agricultural ICTs, including the role of ICTs during the pandemic period. The findings of the study will be important to policy makers to identify the conceivable benefits and weak points of such technologies and to develop policies, solutions, and innovations for empowering the role of these technologies in the agricultural sector with an emphasis on marginalized and vulnerary groups. To the best of the authors' knowledge, this study is the first global research that uses a four-language translated survey, which helps gather accurate data and thus avoid language barriers. The research also considers the responses and perceptions of a large sector of people, not only farmers, who are involved in the agricultural sector. It presents another important unique feature to our study; as in this way, a complete overview can be drawn, reaching the most vulnerable actors along the agro-livestock production chains

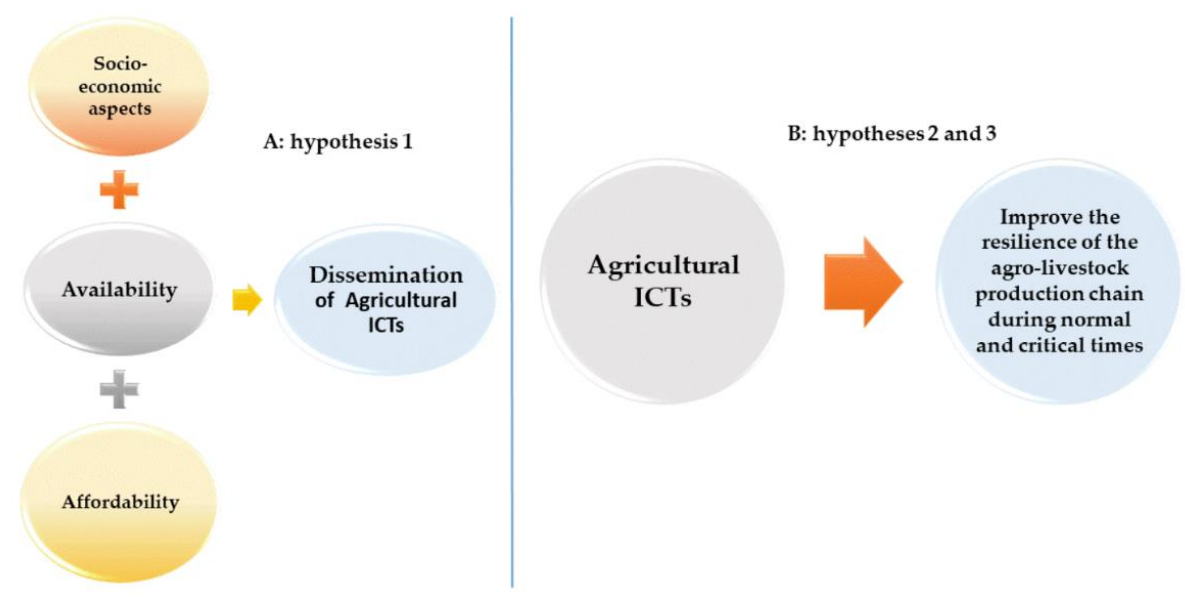

Figure 1. Conceptual framework of the study. (A) Hypothesis 1: socio-economic factors, availability, and affordability can affect the dissemination of agricultural information technologies (ICTs). (B) Hypotheses 2 and 3: agricultural ICTs have positive roles in agro-livestock production chains sustainability during normal and critical times. 


\subsection{Aim of the Study and Design of the Questionnaire}

This study was conducted with the cooperation of researchers from four countries: Egypt, the Kingdom of Saudi Arabia, France, and Spain. The aim of this study was to identify the role of ICTs in farming system sustainability (Figure 2) during the period of the COVID-19 pandemic, and if the pandemic affected the development and the need for such technologies in agricultural sectors. In addition, factors that affect the use of such technologies, such as applicants' attitude and awareness, and the availability of these technologies for those who are involved in farming systems, were considered. For this purpose, a specific mixed questionnaire (including closed- and open-ended questions) was designed and translated into four languages: Arabic, English, French, and Spanish. The questionnaires were designed with the aid of the Google form platform and consisted of four main sections.

\section{Agricultural information and communication technologies}

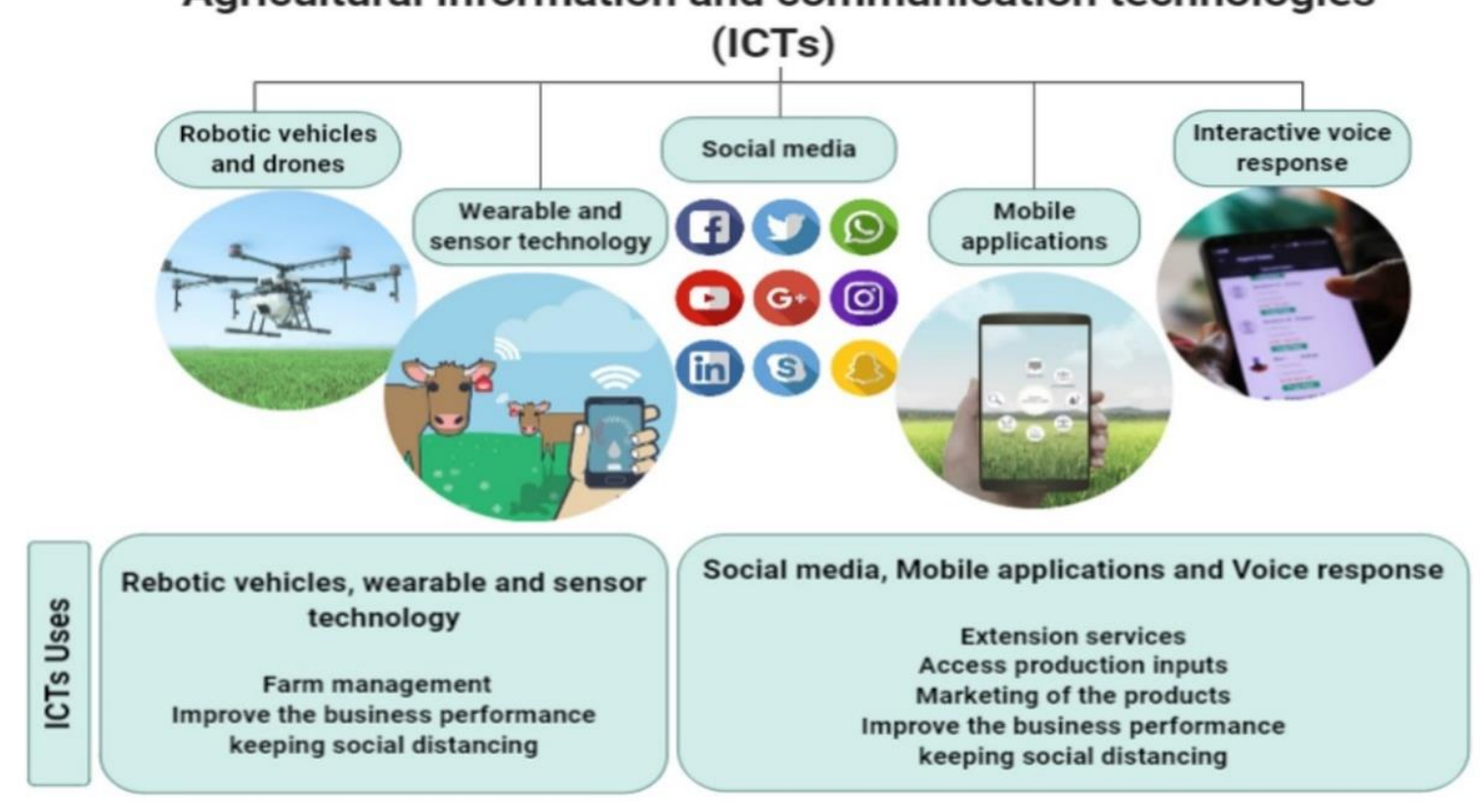

Figure 2. Information and communication technologies (ICTs) used in agricultural sector and their applications.

The first section is an introduction about the importance and aim of the study and the eligibility of the respondents (not less than 18 years old and involved directly or indirectly in farming systems).

The second section includes questions to evaluate the demographic characteristics of participants (gender, age, country, education level, relationship with the agricultural/farming systems, the position of the respondent if working in a farm, and the size of agribusiness).

The third and fourth sections comprise questions that were designed to evaluate: (1) the availability and accessibility of agricultural ICT tools and online-dependent services in general and (2) the importance of agricultural ICTs, the ease of ICT handling and of ICT accessibility, the ICT use under normal and pandemic conditions, the most common type of used ICTs under normal and pandemic conditions, the type of production obstacle solved using agricultural ICTs, and parties concerned with the financial support of agricultural ICTs. Overall, the questionnaire included one open-ended question (country) and 18 closedended questions. The closed-ended questions included single-choice questions, multiplechoice questions, Likert scale questions (including very hard $=5$ points, hard $=4$ points, intermediate $=3$ points, easy $=2$ points, and very easy $=1$ point). Moreover, the mean of the Likert scale was used to express the mean of the responses to the question. In contrast, the open-ended question was a free text answer question. 
Prior to a wider distribution, the questionnaire was preliminarily evaluated for its fluidity and clarity by sharing each copy with 30 applicants who natively speak the language used in each survey. The links of the questionnaires were then shared with those concerned directly (farmers, farm owners, technicians, and laborers) and/or indirectly (professionals, extension guides, and scientists) with farming systems through specific agricultural/livestock social and professional farming networks and websites. The respondents were also asked to circulate the links of the questionnaires among those who belonging to the agricultural sector and connected to different farming systems. The questionnaire was posted on different social networks in different countries and volunteers to answer questions as previously performed in other surveys [23,40].

\subsection{Data Handling and Statistical Analyses}

The questionnaires were allowed to be answered for three months, starting from September to November, 2020 (the period of the emergence of the second pandemic wave) and a total of 516 responses were obtained. Data was collected using an Excel spreadsheet linked to the online Google form questionnaire. All responses were pre-checked for their eligibility and surveys containing illogic answers were discarded. Before subjecting the data for further statistical analyses, the equality of the results was tested using the Levene's test (IBM SPPS Statistics 26), which assesses the null hypothesis so that the input variables from the survey population are in uncorrelated form. In this study, the significance of the Levene's test was set at $p<0.05$. This means that the null hypothesis can be rejected; thus, there is a correlation between the variables [41].

Multiple correspondence analysis (MCA) was applied to detect all possible associations between the studied variables and their categories; the plot (map) showing these associations is shown in the Supplementary Material (Figure S1). The data subset was used to study the relationships between: (1) country status (developed v. developing; classified according to WESP, 2020 [42] on the basis of economic conditions of the country) and (2) the size of agribusiness (classified according to the guidelines of FAO, 2018 [43]; (a) small: total agricultural land of the agricultural holding $<5$ ha and/or animals are bred mainly for own-consumption, (b) medium: total agricultural land of the agricultural holding $\geq 5$ and $<20$ ha and/or animals are bred for both self-consumption and sale, and (c) large: total agricultural land of the agricultural holding $\geq 20$ ha and animals are bred mainly for sale), and (3) the role/position of the respondent (owner, manager, both owner and manager, technician, laborer, others, and not directly working in a farm). Appropriate statistical analyses were performed using SPSS software (IBM SPPS Statistics 26) and presented as count and frequency (\%) for each variable. The Chi-square $\left(\chi^{2}\right)$ test was used to compare frequencies of distributions of the different answers. Statistical significance was set at $p<0.05$.

\section{Results}

\subsection{Demographic Characteristics of Respondents}

Among the 516 respondents of 27 countries, most were from Egypt (24\%), Pakistan $(20 \%)$, Mexico (17\%), and the Kingdom of Saudi Arabia (12\%) (Figure 3). In addition, $71.3 \%$ and $28.7 \%$ of them were citizens in developing and developed countries, respectively. Among the respondents, $59.6 \%$ were male, whereas 39.2\% were female. Moreover, $54.8 \%$ were 18-30 years of age, $27.7 \%$ were $31-50$ years old, and $16.5 \%$ were $>50$ years of age. Most respondents had a university and/or high educational level (86.6\%). The respondents belonged to the agricultural sector as livestock farmers $(16.5 \%)$, plant production farmers $(8.0 \%)$, agro-livestock farmers (16.5\%), other types of relationships (advisers, professionals, and scientists; $41.9 \%$ ), or had no direct relationship (retailers and sellers; $16.9 \%$ ) with the agricultural sector. Of the 516 respondents, 215 were directly involved in the agricultural work in farms, some were managers (3.9\%), owners (3.5\%), owners and managers $(14.9 \%)$, technicians $(16.9 \%)$ or laborers $(2.5 \%)$. The rest of the respondents (301) were indirectly involved in agricultural work in a farm but were advisers, professionals, and scientists 
(44.6\%) or had other roles (13.8\%). Regarding the size of agribusiness, $16.7 \%, 21.8 \%$, and $11.5 \%$ were small, medium, and large businesses. Meanwhile, $49.5 \%$ of the respondents were indirect owners (Table 1).

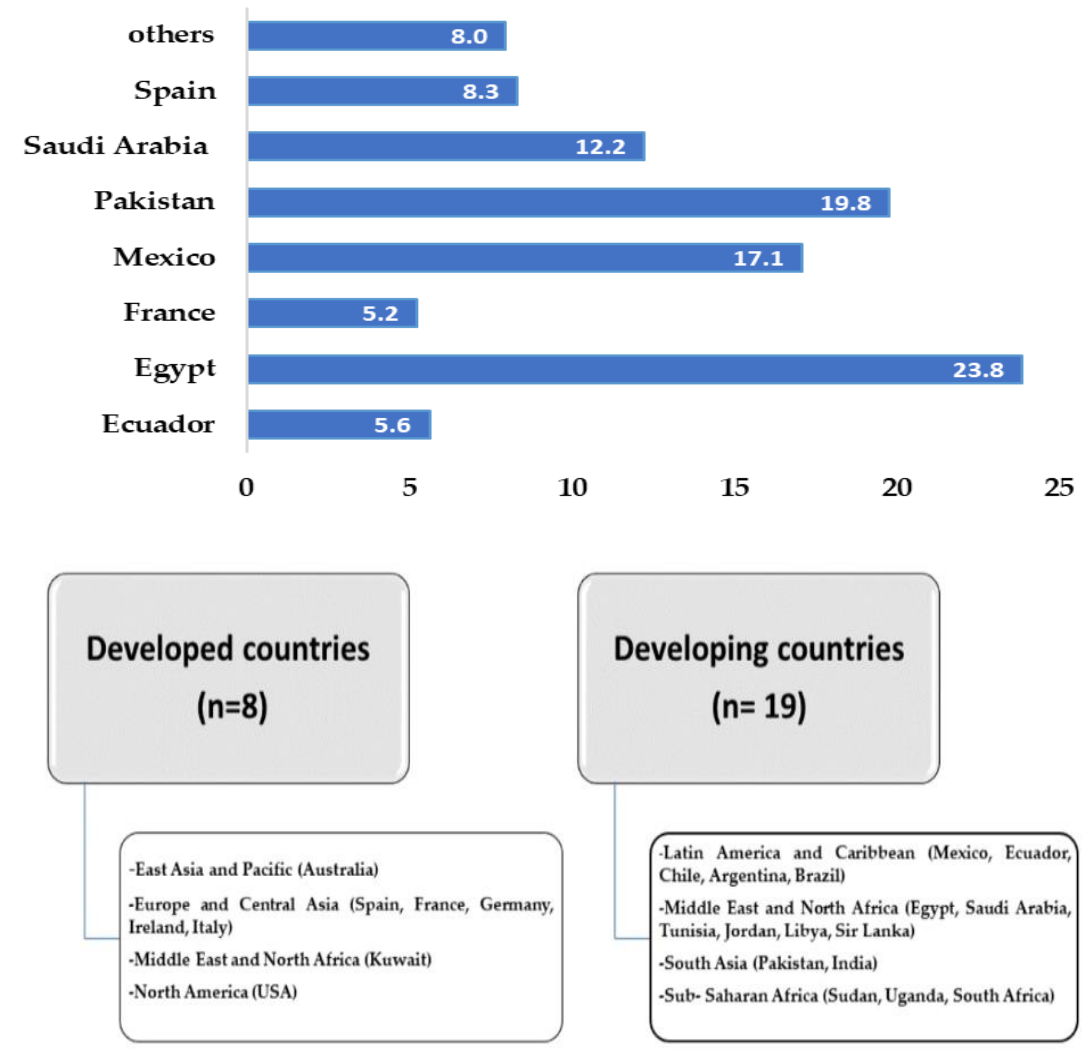

Figure 3. Geographic distribution of the participants (516 responses of 27 countries).

Table 1. Demographic characteristics of the respondents.

\begin{tabular}{lcc}
\hline Variable Category & $\begin{array}{c}\text { No. of Responses } \\
(\mathbf{n}=\mathbf{5 1 6})\end{array}$ & $\begin{array}{c}\text { Frequency } \\
\text { (\%) }\end{array}$ \\
\hline Gender & 308 & 59.6 \\
Male & 202 & 39.2 \\
Female & 6 & 1.2 \\
Do not wish to answer & 283 & 54.8 \\
Age & 143 & 27.7 \\
18 to 30 years of age & 85 & 16.5 \\
31 to 50 years of age & 5 & 1.0 \\
$>51$ years of age & & \\
Do not wish to answer & 148 & 28.7 \\
Country & 368 & 71.3 \\
Developed & & 1.2 \\
Developing & 6 & 4.3 \\
Educational level & 22 & 3.5 \\
Preparatory education & 18 & 86.6 \\
Vocational education & 447 & 1.4 \\
Secondary education & 7 & 3.1 \\
$\quad$ University education (Bachelor) or higher & 16 & \\
None of the previous & & \\
Do not wish to answer & &
\end{tabular}


Table 1. Cont.

\begin{tabular}{lcc}
\hline Variable Category & $\begin{array}{c}\text { No. of Responses } \\
\text { (n = 516) }\end{array}$ & $\begin{array}{c}\text { Frequency } \\
\text { (\%) }\end{array}$ \\
\hline Relation to the agricultural sector & & \\
Plant production farmer & 47 & 8.0 \\
Livestock production farmer & 99 & 16.8 \\
Both fields (crop and livestock) & 84 & 16.5 \\
Other types of relationships (adviser, scientist, etc.) & 207 & 41.7 \\
No direct relationship & 79 & 16.9 \\
Position/role in the farm (if working in a farm) & & \\
Only manager & 20 & 3.9 \\
Only owner & 18 & 3.5 \\
Both owner and manager & 77 & 14.9 \\
Technician & 87 & 16.9 \\
Labor & 13 & 2.5 \\
Other & 71 & 13.8 \\
Do not work in a farm (advisers, professionals, and scientists) & 227 & 44.6 \\
Size of agribusiness & & \\
Small scale & 99 & 16.7 \\
Medium scale & 119 & 21.8 \\
Large scale & 74 & 11.5 \\
Not an owner & 224 & 49.5 \\
\hline
\end{tabular}

\subsection{Awareness, Handling, and Availability of Agricultural ICTs in General}

The data gathering about the awareness, handling, and availability of agricultural ICTs is shown in Table 2. The means of Likert scale for the handling of agricultural ICTs and the ease of accessing agricultural ICTs in general were $3.45 \pm 0.24$ and $3.35 \pm 0.45$, respectively. Most respondents $(75.6 \%, 390 / 516)$ had previous knowledge of agricultural ICTs, and $51.0 \%$ had previous knowledge of agricultural ICTs even before the emergence of the COVID-19 pandemic. The respondents who use agricultural ICTs, in general, revealed that the most common types of used ICTs were social media (Facebook and/or WhatsApp, $27.1 \%)$, online platforms and Internet services $(25.4 \%)$, and mobile applications $(22.4 \%)$. In contrast, interactive voice response $(9.8 \%)$, wearable and sensor technology $(8.0 \%)$, and robotic vehicles and/or drones $(7.2 \%)$ were less commonly used. The respondents who had not used agricultural ICTs yet revealed that the major obstacles preventing the use of agricultural ICTs were the lack of awareness (34.1\%), the high cost of agricultural ICTs $(29.1 \%)$, and unavailability $(27.3 \%)$. The other obstacles preventing the use of agricultural ICTs were the difficulty of use $(6.4 \%)$ and thinking that such technologies are not beneficial technologies (3.2\%).

Table 2. Responses of the participants regarding the awareness, handling, and availability of agricultural information and communication technologies (ICTs).

\begin{tabular}{lcc}
\hline Variable Category & $\begin{array}{c}\text { No. of } \\
\text { Responses }\end{array}$ & $\begin{array}{c}\text { Frequency } \\
\text { (\%) }\end{array}$ \\
\hline Knowledge of ICT applications & 516 & \\
Yes & 390 & 75.6 \\
No & 126 & 24.4 \\
Ease of handling technological tools in general (3.45 \pm 0.24$)$ & 516 & \\
Very hard (1) & 32 & 6.2 \\
Hard (2) & 60 & 11.6 \\
Intermediate (3) & 170 & 33.0 \\
Easy (4) & 150 & 29.0 \\
Very easy (5) & 104 & 20.2 \\
\hline
\end{tabular}


Table 2. Cont.

\begin{tabular}{lcc}
\hline Variable Category & $\begin{array}{c}\text { No. of } \\
\text { Responses }\end{array}$ & $\begin{array}{c}\text { Frequency } \\
\text { (\%) }\end{array}$ \\
\hline Ease of accessing technology services (3.35 \pm 0.45$)$ & 516 & \\
Very hard (1) & 36 & 7.0 \\
Hard (2) & 73 & 14.2 \\
Intermediate (3) & 172 & 33.3 \\
Easy (4) & 142 & 27.5 \\
Very easy (5) & 93 & 18.0 \\
Most common type of used ICTs (if yes) & 1021 & 7.2 \\
Robotic vehicles and/or drones & 81 & 8.1 \\
Wearable and sensor technology & 91 & 25.4 \\
Online platforms and Internet services & 288 & 22.4 \\
Mobile application & 254 & 27.1 \\
Social media (Facebook and/or WhatsApp) & 307 & 9.8 \\
Interactive voice response & 111 & \\
Obstacle preventing the use of ICTs & 220 & 27.3 \\
It is unavailable & 60 & 34.1 \\
I have no idea about agricultural ICTs & 75 & 6.4 \\
Difficult to use & 14 & 29.1 \\
Expensive technologies & 64 & 3.1 \\
Not beneficial technologies & 7 & \\
\hline
\end{tabular}

1 Number of responses differ according to the type of question (one choice, multiple choice, or optional/conditional question).

\subsection{Role of Agricultural ICTs during the COVID-19 Pandemic}

Table 3 presents the role of agricultural ICTs during the COVID-19 pandemic in maintaining farming system sustainability. Most respondents answered that they thought that agricultural ICTs are beneficial technologies either during the normal conditions $(95.0 \%)$ or during the pandemic period $(91.1 \%)$. Nearly half of the respondents $(51.7 \%)$ answered that they use ICTs as routine technologies regardless of the emergence of the pandemic, and $18.2 \%$ answered that they started to use ICTs after the emergence of the pandemic. However, $30.1 \%$ revealed that they had never used agricultural ICTs to execute or monitor their agribusinesses. The respondents who used agricultural ICTs during the pandemic revealed that the most common types of used agricultural ICTs were social media (Facebook and/or WhatsApp, 27.3\%), online platforms and Internet services (26.3\%), and mobile applications (18.4\%). Meanwhile, interactive voice response $(13.0 \%)$, wearable and sensor technology $(8.4 \%)$, and robotic vehicles and/or drones $(6.6 \%)$ were less frequently used. The respondents revealed that during the emergence of the pandemic, the major reason that impacted farming system sustainability was social distancing and movement restrictions $(30.0 \%)$, shortage of labor $(17.7 \%)$, maintenance of precision farm management $(14.8 \%)$, product marketing $(14.2 \%)$, access production inputs $(7.2 \%)$, and others $(16.1 \%)$. According to the respondent answers, the main obstacle that was solved using agricultural ICTs was maintaining precision farm management $(25.7 \%)$, product marketing $(23.8 \%)$, social distancing and movement restrictions (16.5\%), and access production inputs (15.5\%). Last, the respondents answered that agricultural ICTs are financially supported by authority and government $(39.3 \%)$, personal support $(32.0 \%)$, international and local organizations or specific educational support programs (24.0\%), and no support $(18.3 \%)$. 
Table 3. Responses of the participants regarding the role of agricultural information and communication technologies (ICTs) during the pandemic period.

\begin{tabular}{|c|c|c|}
\hline Variable Category & No. of Responses ${ }^{1}$ & Frequency $(\%)$ \\
\hline Time of using ICTs & 516 & \\
\hline After the pandemic & 94 & 18.2 \\
\hline Routine technology regardless the pandemic & 267 & 51.7 \\
\hline Never use & 155 & 30.1 \\
\hline Do ICTs have a beneficial impact in general & 516 & \\
\hline Yes & 490 & 95.0 \\
\hline No & 23 & 4.4 \\
\hline Don't know & 3 & 0.6 \\
\hline Do ICTs have a beneficial impact during the pandemic & 516 & \\
\hline Yes & 470 & 91.1 \\
\hline No & 43 & 8.3 \\
\hline Don't know & 3 & 0.6 \\
\hline Most common type of used ICTs during the pandemic period (if yes) & 1167 & \\
\hline Robotic vehicles and/or drones & 77 & 6.6 \\
\hline Wearable and sensor technology & 98 & 8.4 \\
\hline Online platforms and Internet services & 307 & 26.3 \\
\hline Mobile application & 215 & 18.4 \\
\hline Social media (Facebook and/or WhatsApp) & 318 & 27.3 \\
\hline Interactive voice response & 152 & 13.0 \\
\hline Major production obstacle during the pandemic & 516 & \\
\hline Farm management (extension services, farm monitor, and precision farming) & 67 & 14.8 \\
\hline Access production inputs & 45 & 7.2 \\
\hline Shortage of labor & 89 & 17.7 \\
\hline Social distancing and movement restrictions & 152 & 30.0 \\
\hline Product marketing & 79 & 14.2 \\
\hline Others & 84 & 16.1 \\
\hline Main obstacle solved by using ICTs during the pandemic & 516 & \\
\hline Farm management (extension services, farm monitor, and precision farming) & 133 & 25.7 \\
\hline Access production inputs & 80 & 15.5 \\
\hline Shortage of labor & 55 & 10.7 \\
\hline Social distancing and movement restrictions & 85 & 16.5 \\
\hline Product marketing & 123 & 23.8 \\
\hline Others & 40 & 7.8 \\
\hline Who do support ICTs in your country & 692 & \\
\hline Authority and government & 199 & 28.8 \\
\hline International or local organizations & 125 & 18.1 \\
\hline Specific educational support programs & 122 & 17.6 \\
\hline Personal support & 160 & 23.1 \\
\hline No one & 86 & 12.4 \\
\hline
\end{tabular}

${ }^{1}$ Number of responses differ according to the type of question (one choice, multiple choice, or optional/conditional question).

\subsection{Effect of Country Status}

3.4.1. Relationship between Country Status and the Awareness, Handling, and Availability of Agricultural ICTs

Approximately three-quarters of the respondents from developed countries selected "easy" and "very easy" as responses for the degree of the ease of accessing agricultural ICTs in their countries versus half of those from developing countries $(p<0.05$, Table 4$)$. A total of $34.2 \%$ of the respondents from developing countries versus $29.7 \%$ of those from developed countries revealed that they can handle agricultural ICTs in an intermediate manner $(p<0.05$, Table 4$)$. Among the suggested types of used agricultural ICTs, a significant difference was observed for selecting interactive voice being higher in developing countries; meanwhile, online platforms and Internet services were higher in developed countries. The proportion of robotic vehicles and/or drones (which are very expensive technologies) among the main types of used ICTs is low in developed and developing countries, but with a tendency to be higher in developed countries ( 7.7 vs. $6.9 \%, p=0.124$, Table 4 ). This result is 
logical, but the statistical power of the experimental design does not allow us to detect this difference. Among the major suggested obstacles that prevent the use of agricultural ICTs, respondents from developing countries indicated significantly higher responses toward the cost of agricultural ICTs ( $30.6 \%$ vs. $22.5 \%, p<0.05$, Table 4 ). Interestingly, respondents from developed and developing countries showed the same trend to the answer "it is unavailable." This finding may be ascribed to the fact that respondents were thinking of different technologies in developed countries (more complex and expensive ones) and developing countries (simpler and cheaper ones), as suggested by the results above.

Table 4. Relationship between the degree of country development (developing vs. developed) and responses of the participants regarding the awareness, handling, and availability of agricultural ICTs (frequencies and numbers between brackets).

\begin{tabular}{|c|c|c|}
\hline Variable Category ${ }^{1,2}$ & Developing & Developed \\
\hline Knowledge of ICT applications $\left(X^{2}=519.2, p>0.05\right)$ & 368 & 148 \\
\hline Yes & $76.9(283)$ & $72.3(104)$ \\
\hline No & $23.1(85)$ & $27.7(41)$ \\
\hline Ease of handling technological tools in general $\left(X^{2}=573.2, p<0.001\right)$ & 368 & 148 \\
\hline Very hard (1) & $4.9(18)$ & $9.5(14)$ \\
\hline Hard (2) & $12.8(47)$ & $8.7(13)$ \\
\hline Intermediate (3) & $34.2(126)$ & $29.7(44)$ \\
\hline Easy (4) & $30.4(112)$ & $25.7(38)$ \\
\hline Very easy (5) & $17.7(65)^{b}$ & $26.4^{\mathrm{a}}(39)$ \\
\hline Ease of accessing technology services $\left(X^{2}=528.5, p<0.001\right)$ & 368 & 148 \\
\hline Very hard (1) & $8.4(31)$ & $3.4(5)$ \\
\hline Hard (2) & $17.1^{\mathrm{a}}(63)$ & $6.8^{\mathrm{b}}(10)$ \\
\hline Intermediate (3) & $37.8^{a}(139)$ & $22.3^{\mathrm{b}}(33)$ \\
\hline Easy (4) & $25.5(94)$ & $32.4(48)$ \\
\hline Very easy (5) & $11.2^{b}(41)$ & $35.1^{\mathrm{a}}(52)$ \\
\hline Main type of used ICTs (if yes) $\left(\mathrm{X}^{2}=357.8, p=0.0167\right)$ & 780 & 325 \\
\hline Robotic vehicles and/or drones & $6.9(54)$ & $7.7(27)$ \\
\hline Wearable and sensor technology & $7.3(57)$ & $9.7(34)$ \\
\hline Online platforms and Internet services & $24.4^{\mathrm{b}}(190)$ & $27.8^{\mathrm{a}}(98)$ \\
\hline Mobile application & $21.9(171)$ & $23.6(83)$ \\
\hline Social media (Facebook and/or WhatsApp) & $29.1(227)$ & $22.7(80)$ \\
\hline Interactive voice response & $10.4^{\mathrm{a}}(81)$ & $8.5^{\mathrm{b}}(30)$ \\
\hline Main obstacle preventing the use of ICTs $\left(X^{2}=23.3, p<0.001\right)$ & 180 & 40 \\
\hline It is unavailable & $26.7(48)$ & $30.0(12)$ \\
\hline I have no idea about agricultural ICTs & $33.8(61)$ & $35.0(14)$ \\
\hline Difficult to use & $6.1(11)$ & $7.5(3)$ \\
\hline Expensive technologies & $30.6^{\mathrm{a}}(55)$ & $22.5^{b}(9)$ \\
\hline Not beneficial technologies & $2.8(5)$ & $5.0(2)$ \\
\hline
\end{tabular}

${ }^{1}$ Number of responses and numbers between brackets differ according to the type of question (one choice, multiple choice, or optional/conditional question). ${ }^{2} \mathrm{X}^{2}$ refers to correlation value estimated by Chi-square test, $p$ refers to the significance of the correlation between two variables, and different superscript letters $(\mathrm{a}, \mathrm{b})$ indicate means with significant statistical differences at $p<0.05$.

\subsubsection{Relationship between Country Status and the Role of Agricultural ICTs}

Despite the equal degree of answers of the respondents from developing and developed countries regarding the agricultural ICT benefits during normal and/or during the pandemic period, $62.8 \%$ of the respondents from developed countries indicated that they use agricultural ICTs as routine technologies even before the pandemic versus $47.4 \%$ of those from developing countries. Approximately $21.2 \%$ of the respondents from developing countries shared that they started to use ICTs after the emergence of the pandemic versus $10.8 \%$ of those from developed countries. The same trend was also observed for the answer "never use" ( $p<0.05$, Table 5). During the pandemic, the respondents from developing countries indicated significantly higher responses toward social media and mobile applications as the main technologies used for agricultural ICTs, whereas the responses for robotic vehicles and/or drones were significantly higher for those from developed 
countries $(p<0.05$, Table 5). Among the suggested production obstacles raised during the pandemic, the respondents from developing countries (16.8\%) expressed significantly higher responses toward product marketing versus $11.4 \%$ of those from developed countries. Meanwhile, the main obstacle selected by those from developed countries was the shortage of labor $(21.0 \%$ vs. $15.8 \%, p<0.05$, Table 5$)$.

Table 5. Relationship between the degree of country development (developing vs. developed) and responses of the participants regarding the role of agricultural ICTs during the pandemic period (frequencies and numbers between brackets).

\begin{tabular}{|c|c|c|}
\hline Variable Category $^{1,2}$ & Developing & Developed \\
\hline Time of using ICTs $\left(X^{2}=530.3, p<0.001\right)$ & 367 & 148 \\
\hline After the pandemic & $21.2^{\mathrm{a}}(78)$ & $10.8^{\mathrm{b}}(16)$ \\
\hline Routine technology regardless of the pandemic & $47.4^{\mathrm{b}}(174)$ & $62.8^{\text {a }}(93)$ \\
\hline Never use & $31.4^{\text {a }}(115)$ & $26.4^{\mathrm{b}}(39)$ \\
\hline Do ICTs have a beneficial impact in general $\left(\mathrm{X}^{2}=518.0, p>0.05\right)$ & 386 & 148 \\
\hline Yes & $94.8(349)$ & $95.3(141)$ \\
\hline No & $4.4(15)$ & $4.7(7)$ \\
\hline Don't know & $0.8(4)$ & $0.0(0)$ \\
\hline Do ICTs have a beneficial impact during the pandemic $\left(X^{2}=519.2, p>0.05\right)$ & 368 & 148 \\
\hline Yes & $90.8(334)$ & $91.9(136)$ \\
\hline No & $8.4(30)$ & $8.1(12)$ \\
\hline Don't know & $0.8(4)$ & $0.0(0)$ \\
\hline Main type of ICTs during the pandemic period (if yes) $\left(X^{2}=5.56, p=0.035\right)$ & 828 & 439 \\
\hline Robotic vehicles and/or drones & $6.6^{\mathrm{b}}(55)$ & $27.8^{\mathrm{a}}(122)$ \\
\hline Wearable and sensor technology & $8.6(71)$ & $6.2(27)$ \\
\hline Online platforms and Internet services & $25.4^{\mathrm{a}}(210)$ & $22.1^{\mathrm{b}}(97)$ \\
\hline Mobile application & $17.8(147)$ & $15.4(68)$ \\
\hline Social media (Facebook and/or WhatsApp) & $28.6^{\mathrm{a}}(237)$ & $18.5^{\mathrm{b}}(81)$ \\
\hline Interactive voice response & $13.0(108)$ & $10.0(44)$ \\
\hline Major production obstacle during the pandemic $\left(X^{2}=523.1, p<0.001\right)$ & 368 & 148 \\
\hline Farm management (extension services, farm monitor, and precision farming) & $12.5(46)$ & $14.2(21)$ \\
\hline Access production inputs & $9.5(35)$ & $6.8(10)$ \\
\hline Shortage of labor & $15.8^{\mathrm{b}}(58)$ & $21.0^{\mathrm{a}}(31)$ \\
\hline Social distancing and movement restrictions & $28.8(106)$ & $31.1(46)$ \\
\hline Product marketing & $16.8^{\mathrm{a}}(62)$ & $11.4^{\mathrm{b}}(17)$ \\
\hline Others & $16.6(61)$ & $15.5(23)$ \\
\hline Main obstacle solved by using ICTs during the pandemic $\left(X^{2}=121.06, p<0.001\right)$ & 364 & 152 \\
\hline Farm management (extension services, farm monitor, and precision farming) & $23.6(82)$ & $30.6(47)$ \\
\hline Access production inputs & $19.2^{\mathrm{a}}(66)$ & $8.3^{\mathrm{b}}(13)$ \\
\hline Shortage of labor & $9.6^{\mathrm{b}}(33)$ & $17.4^{\mathrm{a}}(27)$ \\
\hline Social distancing and movement restrictions & $17.9(62)$ & $20.8(32)$ \\
\hline Product marketing & $26.1^{\mathrm{a}}(90)$ & $17.4^{\mathrm{b}}(25)$ \\
\hline Others & $3.6(13)$ & $5.5(8)$ \\
\hline Who do support ICTs in your country $\left(\mathrm{X}^{2}=248.55, p<0.001\right)$ & 489 & 202 \\
\hline Authority and government & $27.4(134)$ & $32.2(65)$ \\
\hline International or local organizations & $17.8(87)$ & $18.3(37)$ \\
\hline Specific educational support programs & $18.8(92)$ & $14.8(30)$ \\
\hline Personal support & $23.7(116)$ & $21.8(44)$ \\
\hline No one & $12.3(60)$ & $12.9(26)$ \\
\hline
\end{tabular}

${ }^{1}$ Number of responses, numbers between brackets, differ according to the type of question (one choice, multiple choice, or optional/conditional question). ${ }^{2} \mathrm{X}^{2}$ refers to correlation value estimated by Chi-square test, $p$ refers to the significance of the correlation between two variables, and different superscript letters $(a, b)$ indicate means with significant statistical differences at $p<0.05$. 
Compared with the respondents from developed countries, those from developing countries indicated significantly higher responses toward product marketing $(26.1 \% \mathrm{vs}$. $17.4 \%, p<0.05$, Table 5$)$ and access production inputs $(19.2 \%$ vs. $8.3 \%, p<0.05$, Table 5$)$ as the main obstacles solved by applying ICTs. The shortage of labor was significantly higher for those from developed countries than for those from developing countries $(17.4 \%$ vs. $9.6 \%, p<0.05$, Table 5)

\subsection{Effect of Agribusiness Size}

3.5.1. Relationship between Size of Agribusiness and the Awareness, Handling, and Availability of Agricultural ICTs

Approximately $15.2 \%$ and $17.7 \%$ of the respondents respectively owning small- and medium-scale agribusinesses versus $31.1 \%$ of those owning large-scale agribusinesses revealed that they easily handle agricultural ICTs $(p<0.05$, Table 6$)$. Among the major obstacles that prevent the use of agricultural ICTs, respondents owning small-scale agribusinesses indicated significantly higher responses (30.4\%) toward the unaffordability of the technologies than those owning medium-scale agribusinesses $(21.1 \%)$ and large-scale agribusinesses $(14.3 \%)(p<0.05$, Table 6$)$.

Table 6. Relationship between the size of agribusiness and responses of the participants regarding the awareness, handling, and availability of agricultural ICTs (frequencies and numbers between brackets).

\begin{tabular}{|c|c|c|c|}
\hline Variable Category ${ }^{1,2}$ & Small-Scale & Medium-Scale & Large-Scale \\
\hline Knowledge of ICT applications $\left(\mathrm{X}^{2}=0.932, p=0.627\right)$ & 99 & 119 & 74 \\
\hline Yes & $80.8(80)$ & $78.2(93)$ & $83.8(62)$ \\
\hline No & $19.2(19)$ & $21.8(26)$ & $16.2(12)$ \\
\hline Ease of handling technological tools in general $\left(X^{2}=15.9, p=0.041\right)$ & 99 & 119 & 74 \\
\hline Very hard (1) & $10.1^{\mathrm{a}}(10)$ & $4.2^{\mathrm{b}}(5)$ & $1.4^{\mathrm{b}}(1)$ \\
\hline Hard (2) & $13.1(13)$ & $10.1(12)$ & $14.9(11)$ \\
\hline Intermediate (3) & $38.4(38)$ & $38.6(46)$ & $33.8(25)$ \\
\hline Easy (4) & $23.2(23)$ & $29.4(35)$ & $18.9(14)$ \\
\hline Very easy (5) & $15.2^{b}(15)$ & $17.7^{\mathrm{b}}(21)$ & $31.1^{\mathrm{a}}(23)$ \\
\hline Ease of accessing technology services $\left(X^{2}=11.3, p=0.183\right)$ & 99 & 119 & 74 \\
\hline Very hard (1) & $11.2(11)$ & $5.0(6)$ & $13.5(10)$ \\
\hline Hard (2) & $20.2(20)$ & $11.8(14)$ & $9.5(7)$ \\
\hline Intermediate (3) & $33.3(33)$ & $37.0(44)$ & $31.1(23)$ \\
\hline Easy (4) & $23.2(23)$ & $26.1(31)$ & $27.0(20)$ \\
\hline Very easy (5) & $12.1(12)$ & $20.1(24)$ & $18.9(14)$ \\
\hline Main type of used ICTs (if yes) $\left(X^{2}=452.23, p=0.032\right)$ & 201 & 262 & 197 \\
\hline Robotic vehicles and/or drones & $8.5(17)$ & $4.9(13)$ & $8.6(17)$ \\
\hline Wearable and sensor technology & $11.0(22)$ & $5.4(14)$ & $11.2(22)$ \\
\hline Online platforms and Internet services & $21.4^{\mathrm{b}}(43)$ & $26.3^{\mathrm{a}}(69)$ & $24.9^{\mathrm{b}}(49)$ \\
\hline Mobile application & $19.3(39)$ & $23.3(61)$ & $23.9(47)$ \\
\hline Social media (Facebook and/or WhatsApp) & $27.4(55)$ & $28.6(75)$ & $22.8(45)$ \\
\hline Interactive voice response & $12.4(25)$ & $11.5(30)$ & $8.6(17)$ \\
\hline Main obstacle preventing the use of ICTs $\left(X^{2}=22.7, p=0.012\right)$ & 64 & 57 & 21 \\
\hline It is unavailable & $30.4^{\mathrm{a}}(17)$ & $21.1^{\mathrm{b}}(12)$ & $14.3^{\mathrm{ab}}(3)$ \\
\hline I have no idea about agricultural ICTs & $28.6(16)$ & $29.8(17)$ & $38.1(8)$ \\
\hline Difficult to use & $7.1(12)$ & $8.7(5)$ & $14.3(3)$ \\
\hline Expensive technologies & $28.5(16)$ & $40.4(23)$ & $33.3(7)$ \\
\hline Not beneficial technologies & $5.4(3)$ & $0.0(0)$ & $0.0(0)$ \\
\hline
\end{tabular}

${ }^{1}$ Number of responses, numbers between brackets, differ according to the type of question (one choice, multiple choice, or optional/conditional question). ${ }^{2} \mathrm{X}^{2}$ refers to correlation value estimated by Chi-square test, $p$ refers to the significance of the correlation between two variables, and different superscript letters $(\mathrm{a}, \mathrm{b})$ indicate means with significant statistical differences at $p<0.05$. 


\subsubsection{Relationship between Size of Agribusiness and the Role of Agricultural ICTs}

Approximately $27.3 \%$ and $21.9 \%$ of the respondents respectively owning small- and medium-scale agribusinesses versus $17.6 \%$ of those owning large-scale agribusinesses revealed that they started using agricultural ICTs after the emergence of the pandemic $(p<0.05$, Table 7$)$. A total of $72.8 \%$ and $52.1 \%$ of the respondents, respectively, owning large- and medium-scale agribusinesses indicated that the agricultural ICTs were routine applications regardless of the emergence of the pandemic versus $35.4 \%$ of those owning small-scale agribusinesses. For respondents owning small-scale agribusinesses, 33.0\% indicated that the main obstacle solved using agricultural ICTs was product marketing, whereas $24.4 \%$ of those owning medium-scale agribusinesses selected "access production inputs" ( $p<0.05$, Table 7).

Table 7. Relationship between the size of agribusiness and responses of the participants regarding the role of agricultural ICTs during the pandemic period (frequencies and numbers between brackets).

\begin{tabular}{|c|c|c|c|}
\hline Variable Category $^{1,2}$ & Small-Scale & Medium-Scale & Large-Scale \\
\hline Time of using ICTs $\left(X^{2}=26.3, p<0.001\right)$ & 99 & 119 & 74 \\
\hline After the pandemic & $27.3^{\mathrm{a}}(27)$ & $21.8^{\mathrm{a}}(26)$ & $17.5^{\mathrm{b}}(13)$ \\
\hline Routine technology regardless the pandemic & $35.3^{b}(35)$ & $52.1^{\mathrm{a}}(62)$ & $73.0^{\mathrm{a}}(54)$ \\
\hline Never use & $37.4^{\mathrm{a}}(37)$ & $26.1^{\mathrm{a}}(31)$ & $9.5^{\mathrm{b}}(7)$ \\
\hline Do ICTs have a beneficial impact in general $\left(\mathrm{X}^{2}=22.7, p=0.728\right)$ & 99 & 119 & 74 \\
\hline Yes & $93.9(93)$ & $95.8(114)$ & $97.3(72)$ \\
\hline No & $6.1(6)$ & $4.2(5)$ & $2.7(2)$ \\
\hline Do ICTs have a beneficial impact during the pandemic $\left(X^{2}=2.3, p=0.684\right)$ & 99 & 119 & 74 \\
\hline Yes & $91.9(68)$ & $89.99(107)$ & $90.9(90)$ \\
\hline No & $8.1(6)$ & $10.1(12)$ & $8.1(8)$ \\
\hline Don't know & 0.0 & 0.0 & $1.0(1)$ \\
\hline Main type of used ICTs during the pandemic (if yes) $\left(X^{2}=157.2, p=0.01\right)$ & 196 & 277 & 176 \\
\hline Robotic vehicles and/or drones & $8.2(16)$ & $5.8(16)$ & $5.7(10)$ \\
\hline Wearable and sensor technology & $11.7^{\mathrm{a}}(23)$ & $7.9^{b}(22)$ & $8.0^{\mathrm{b}}(14)$ \\
\hline Online platforms and Internet services & $23.5^{\mathrm{b}}(46)$ & $25.6^{\mathrm{b}}(71)$ & $31.8^{a}(56)$ \\
\hline Mobile application & $15.3(30)$ & $18.8(52)$ & $17.6(56)$ \\
\hline Social media (Facebook and/or WhatsApp) & $29.6(58)$ & $26.4(73)$ & $23.3(41)$ \\
\hline Interactive voice response & $11.7(23)$ & $15.5(43)$ & $13.6(24)$ \\
\hline Major production obstacle during the pandemic $\left(X^{2}=16.7, p=0.01\right)$ & 99 & 119 & 74 \\
\hline Farm management (extension services, farm monitor, and precision farming) & $21.2^{\mathrm{a}}(21)$ & $11.8^{\mathrm{b}}(14)$ & $12.1^{\mathrm{b}}(9)$ \\
\hline Access production inputs & $8.1(8)$ & $14.3(17)$ & $14.9(11)$ \\
\hline Shortage of labor & $18.2(18)$ & $22.7(27)$ & $13.5(10)$ \\
\hline Social distancing and movement restrictions & $26.2(26)$ & $26.1(31)$ & $25.7(19)$ \\
\hline Product marketing & $15.2(15)$ & $7.6(21)$ & $18.9(14)$ \\
\hline Others & $11.1(11)$ & $7.5(9)$ & $14.9(11)$ \\
\hline Main obstacle solved by using ICTs during the pandemic $\left(\mathrm{X}^{2}=10.8, p=0.038\right)$ & 99 & 119 & 74 \\
\hline Farm management (extension services, farm monitor, and precision farming) & $33.3(33)$ & $21.0(25)$ & $33.7(25)$ \\
\hline Access production inputs & $14.1^{\mathrm{b}}(14)$ & $24.4^{\mathrm{a}}(29)$ & $9.5^{b}(7)$ \\
\hline Shortage of labor & $5.1(5)$ & $10.1(12)$ & $9.5(7)$ \\
\hline Social distancing and movement restrictions & $9.1(9)$ & $8.4(10)$ & $17.6(13)$ \\
\hline Product marketing & $33.3^{\text {a }}(33)$ & $27.7^{\mathrm{b}}(33)$ & $21.6^{\mathrm{b}}(16)$ \\
\hline Others & $5.1(5)$ & $8.4(10)$ & $8.1(6)$ \\
\hline Who do support ICTs in your country $\left(\mathrm{X}^{2}=170.4, p=0.117\right)$ & 128 & 152 & 106 \\
\hline Authority and government & $30.5(39)$ & $26.3(40)$ & $30.2(32)$ \\
\hline International or local organizations & $24.2(31)$ & $21.1(32)$ & $22.6(24)$ \\
\hline Specific educational support programs & $14.8(19)$ & $18.4(28)$ & $17.0(18)$ \\
\hline Personal support & $20.3(26)$ & $25.0(38)$ & $18.9(20)$ \\
\hline No one & $10.2(13)$ & $9.2(14)$ & $11.3(12)$ \\
\hline
\end{tabular}

${ }^{1}$ Number of responses, numbers between brackets, differ according to the type of question (one choice, multiple choice, or optional/conditional question). ${ }^{2} \mathrm{X}^{2}$ refers to correlation value estimated by Chi-square test, $p$ refers to the significance of the correlation between two variables, and superscript letters $(a, b)$ indicate means with significant statistical differences at $p<0.05$. 


\subsection{Effect of Role/Position in the Farm}

3.6.1. Relationship between Role/Position in the Farm and the Awareness, Handling, and Availability of Agricultural ICTs

The subgroup analyses for the relationships between the role/position in the farm and the degree of ease and accessibility of agricultural ICTs suggested that $30.8 \%$ and $53.9 \%$ of laborers selected "hard level" as a response for both questions compared with other roles/positions $(p<0.05$, Table 8$)$. Laborers showed the lowest responses for the use of online platforms and Internet services as agricultural ICTs, whereas the highest responses were for social media $(p<0.05$, Table 8$)$. Regarding the reason preventing the use of agricultural ICTs, $60.0 \%$ of managers (only) selected "expensive technologies", $55.6 \%$ of owners (only) chose "unavailable technologies", and $46.2 \%$ of laborers selected "I have no idea about agricultural ICTs" ( $p<0.05$, Table 8$)$.

3.6.2. Relationship between Role/Position in the Farm and the Role of Agricultural ICTs

The respondents who acted as owners and managers (34.6\%) revealed that they started to use agricultural ICTs after the emergence of the pandemic, whereas those who acted as managers only $(70.0 \%)$ or technicians $(62.1 \%)$ expressed that ICTs were routinely used regardless of the emergence of the pandemic. Meanwhile, $46.2 \%$ of laborers shared that they have never used such technologies (Table 9, $p<0.05$ ). Technicians expressed that the main obstacle solved using agricultural ICTs was product marketing, whereas managers/owners and laborers expressed that it was farm management (Table $9, p<0.05$ ). 


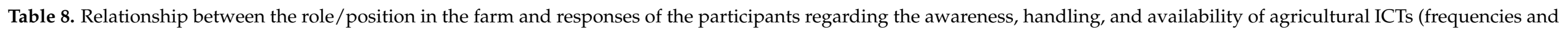
numbers between brackets).

\begin{tabular}{|c|c|c|c|c|c|c|c|}
\hline Variable Category ${ }^{1,2}$ & $\begin{array}{c}\text { Only } \\
\text { Manager }\end{array}$ & $\begin{array}{l}\text { Only } \\
\text { Owner }\end{array}$ & $\begin{array}{c}\text { Both Owner and } \\
\text { Manager }\end{array}$ & Technician & Labor & Other & $\begin{array}{l}\text { Do Not Work in } \\
\text { a Farm }\end{array}$ \\
\hline Knowledge of ICT applications $\left(X^{2}=230.1, p<0.001\right)$ & 20 & 18 & 77 & 87 & 13 & 71 & 227 \\
\hline Yes & $85.0^{\mathrm{a}}(17)$ & $61.1^{\mathrm{b}}(11)$ & $90.9^{\mathrm{a}}(70)$ & $75.9^{\mathrm{ab}}(66)$ & $38.5^{\mathrm{c}}(5)$ & $73.2^{\mathrm{ab}}(52)$ & $73.1(166)$ \\
\hline Ease of handling technological tools in general $\left(X^{2}=256.2, p<0.001\right)$ & 20 & 18 & 77 & 87 & 13 & 71 & 227 \\
\hline Very hard (1) & $5.0^{\mathrm{b}}(1)$ & $5.6^{\mathrm{b}}(1)$ & $9.1^{\mathrm{b}}(7)$ & $14.9^{\mathrm{a}}(13)$ & $7.7^{\mathrm{b}}(1)$ & $5.6^{\mathrm{b}}(4)$ & $4.0^{\mathrm{b}}(9)$ \\
\hline Hard (2) & $15.0^{\mathrm{b}}(3)$ & $22.2^{a b}(4)$ & $6.5^{\mathrm{c}}(5)$ & $9.2^{\mathrm{c}}(8)$ & $30.8^{\text {a }}(4)$ & $16.9(12)^{b}$ & $16.3^{\mathrm{b}}(37)$ \\
\hline Intermediate (3) & $30.0(6)$ & $33.3(6)$ & $28.6(22)$ & $40.2(35)$ & $46.1(6)$ & $33.8(24)$ & $31.6(72)$ \\
\hline Very easy (5) & $20.0^{\mathrm{ab}}(4)$ & $27.8^{\text {a }}(5)$ & $23.3^{\mathrm{ab}}(18)$ & $8.1^{\mathrm{b}}(7)$ & $0.0^{\mathrm{b}}(0)$ & $16.9^{\mathrm{ab}}(12)$ & $20.3^{\mathrm{ab}}(46)$ \\
\hline Ease of accessing technology services $\left(X^{2}=243.6, p<0.001\right)$ & 20 & 18 & 77 & 87 & 13 & 71 & 227 \\
\hline Very hard (1) & $0.0^{\mathrm{b}}(0)$ & $0.0^{\mathrm{b}}(0)$ & $3.8^{\mathrm{b}}(3)$ & $3.5^{\mathrm{b}}(3)$ & $15.4^{\mathrm{a}}(2)$ & $8.5^{\mathrm{ab}}(6)$ & $7.9^{\mathrm{ab}}(18)$ \\
\hline Hard (2) & $5.0^{\mathrm{b}}(1)$ & $11.11^{\mathrm{b}}(2)$ & $7.8^{\mathrm{b}}(6)$ & $12.6^{\mathrm{b}}(11)$ & $53.8^{\mathrm{a}}(7)$ & $12.7^{\mathrm{b}}(9)$ & $10.6^{\mathrm{b}}(24)$ \\
\hline Intermediate (3) & $35.0^{\mathrm{a}}(7)$ & $38.9^{\mathrm{a}}(7)$ & $28.6^{\mathrm{ab}}(22)$ & $42.5^{\mathrm{a}}(37)$ & $15.4^{\mathrm{b}}(2)$ & $33.8^{\text {a }}(24)$ & $31.3^{\text {a }}(71)$ \\
\hline Easy (4) & $35.0^{\mathrm{a}}(7)$ & $33.3^{a}(6)$ & $33.8^{\mathrm{a}}(26)$ & $29.9^{\mathrm{a}}(26)$ & $0.0^{\mathrm{b}}(0)$ & $19.7^{\mathrm{ab}}(14)$ & $30.8^{\mathrm{a}}(70)$ \\
\hline Very easy (5) & $25.0(5)$ & $16.7(3)$ & $26.0(20)$ & $11.5(10)$ & $15.4(2)$ & $25.4(18)$ & $19.4(44)$ \\
\hline Main type of used ICTs (if yes) $\left(X^{2}=358.5, p=0.021\right)$ & 59 & 25 & 177 & 216 & 24 & 176 & 455 \\
\hline Online platforms and Internet services & $8.5^{\mathrm{a}}(16)$ & $8.0^{\mathrm{a}}(6)$ & $9.0^{a}(46)$ & $7.9^{\mathrm{ab}}(53)$ & $4.2(2) \mathrm{b}$ & $9.9^{\text {a }}(46)$ & $8.1^{\mathrm{a}}(117)$ \\
\hline Mobile application & $18.6(12)$ & $12.0(4)$ & $7.4(43)$ & $12.0(50)$ & $8.3(6)$ & $19.0(32)$ & $7.3(104)$ \\
\hline Social media (Facebook and/or WhatsApp) & $20.3^{\mathrm{ab}}(13)$ & $16.0^{\mathrm{b}}(6)$ & $24.2^{\mathrm{a}}(43)$ & $23.2^{\mathrm{a}}(64)$ & $25.0^{\mathrm{a}}(9)$ & $26.5^{\mathrm{a}}(43)$ & $22.9^{\mathrm{ab}}(126)$ \\
\hline Interactive voice response & $22.0^{\mathrm{b}}(11)$ & $24.0^{\mathrm{b}}(3)$ & $24.3^{\mathrm{b}}(13)$ & $29.6^{\mathrm{ab}}(26)$ & $37.5(2)^{a}$ & $35.5^{\mathrm{a}}(23)$ & $27.7^{\mathrm{ab}}(33)$ \\
\hline Main obstacle preventing the use of ICTs $\left(X^{2}=64.4, p=0.002\right)$ & 5 & 9 & 38 & 27 & 13 & 32 & 97 \\
\hline It is unavailable & $0.0^{\mathrm{c}}(0)$ & $55.6^{\mathrm{a}}(5)$ & $15.8^{\mathrm{ab}}(6)$ & $29.6^{\mathrm{b}}(8)$ & $7.7^{\mathrm{c}}(1)$ & $40.7^{\mathrm{a}}(13)$ & $27.8^{\mathrm{b}}(27)$ \\
\hline I have no idea about agricultural ICTs & $40.0^{\mathrm{a}}(2)$ & $0.0^{\mathrm{c}}(0)$ & $23.7^{a b}(9)$ & $33.33^{b}(9)$ & $46.2(6)^{\mathrm{a}}$ & $28.13^{a b}(9)$ & $42.3^{\mathrm{a}}(41)$ \\
\hline Difficult to use & $0.0^{\mathrm{c}}(0)$ & $11.1^{\mathrm{b}}(1)$ & $18.4^{\text {a }}(7)$ & $0.0^{\mathrm{c}}(0)$ & $7.7^{\mathrm{ab}}(1)$ & $3.1^{\mathrm{bc}}(1)$ & $4.1^{\mathrm{bc}}(4)$ \\
\hline Expensive technologies & $60.0^{a}(3)$ & $22.2^{\mathrm{c}}(2)$ & $42.1^{\mathrm{b}}(16)$ & $33.3^{b}(9)$ & $38.4^{b}(5)$ & $25.0^{\mathrm{bc}}(8)$ & $22.7^{\text {bc }}(22)$ \\
\hline Not beneficial technologies & $0.0^{\mathrm{b}}(0)$ & $11.1^{\mathrm{a}}(1)$ & $0.0^{\mathrm{b}}(0)$ & $3.7^{\mathrm{b}}(1)$ & $0.0^{\mathrm{b}}(0)$ & $3.1^{\mathrm{b}}(1)$ & 3. $1^{b}(3)$ \\
\hline
\end{tabular}

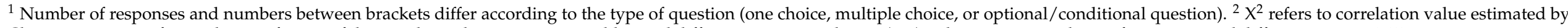
Chi-square test, $p$ refers to the significance of the correlation between two variables, and different superscript letters $(\mathrm{a}-\mathrm{c})$ indicate means with significant statistical differences at $p<0.05$. 
Table 9. Relationship between the role/position in the farm and the role of ICTs during the pandemic period (frequencies and numbers between brackets).

\begin{tabular}{|c|c|c|c|c|c|c|c|}
\hline Variable Category ${ }^{1,2}$ & $\begin{array}{c}\text { Only } \\
\text { Manager }\end{array}$ & $\begin{array}{l}\text { Only } \\
\text { Owner }\end{array}$ & $\begin{array}{l}\text { Both Owner } \\
\text { and Manager }\end{array}$ & Technician & Labor & Other & $\begin{array}{c}\text { Do Not Work in } \\
\text { a Farm }\end{array}$ \\
\hline Time of using ICTs $\left(X^{2}=259.0, p<0.001\right)$ & 20 & 18 & 81 & 87 & 13 & 71 & 226 \\
\hline After the pandemic & $25.0^{\mathrm{ab}}(5)$ & $16.7^{\mathrm{b}}(3)$ & $34.6^{\mathrm{a}}(28)$ & $24.1^{\mathrm{ab}}(21)$ & $23.1^{\mathrm{ab}}(3)$ & $21.1^{\mathrm{ab}}(15)$ & $10.1^{\mathrm{b}}(23)$ \\
\hline Routine technology regardless the pandemic & $70.0^{\mathrm{a}}(14)$ & $38.9^{b}(7)$ & $50.6^{\mathrm{ab}}(41)$ & $62.1^{\mathrm{a}}(54)$ & $30.8^{\mathrm{b}}(4)$ & $47.9(34)^{a b}$ & $48.7^{\mathrm{ab}}(110)$ \\
\hline Do ICTs have a beneficial impact in general $\left(X^{2}=210.1, p=0.621\right)$ & 20 & 18 & 81 & 87 & 13 & 71 & 226 \\
\hline 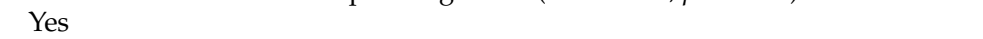 & $100(20)$ & $94.4(17)$ & $98.0(79)$ & $96.5(84)$ & $100(13)$ & $95.8(68)$ & $93.8(213)$ \\
\hline No & $0.0(0)$ & $5.6(1)$ & $2.0(2)$ & $3.5(3)$ & $0.0(0)$ & $4.2(3)$ & $6.2(14)$ \\
\hline Do ICTs have a beneficial impact during the pandemic $\left(X^{2}=218.6, p<0.001\right)$ & 20 & 18 & 81 & 87 & 13 & 71 & 226 \\
\hline Yes & $95.0^{\mathrm{a}}(19)$ & $77.8^{\mathrm{b}}(14)$ & $92.6^{\mathrm{a}}(75)$ & $97.7^{\mathrm{a}}(85)$ & $92.3^{\mathrm{a}}(12)$ & $88.7^{\mathrm{ab}}(63)$ & $89.9^{\mathrm{ab}}(203)$ \\
\hline No & $5.0(1)$ & $22.2(4)$ & $7.4(6)$ & $2.30(2)$ & $7.7(1)$ & $9.9(7)$ & $9.7(22)$ \\
\hline Don't know & 0.0 & 0.0 & 0.0 & 0.0 & 0.0 & $1.4(1)$ & $0.4(1)$ \\
\hline Main type of used ICTs during the pandemic (if yes) $\left(X^{2}=244.5, p=0.045\right)$ & 52 & 24 & 180 & 212 & 26 & 172 & 492 \\
\hline Robotic vehicles and/or drones & $28.8(15)$ & $29.2(7)$ & $27.2(49)$ & $24.5(52)$ & $23.1(6)$ & $29.1(50)$ & $25.6(126)$ \\
\hline Wearable and sensor technology & $5.8(3)$ & $8.3(2)$ & $7.8(14)$ & $4.7(10)$ & $7.7(2)$ & $5.8(10)$ & $7.3(36)$ \\
\hline Online platforms and Internet services & $7.7(4)$ & $8.3(2)$ & $11.7(21)$ & $7.1(15)$ & $3.84(1)$ & $9.3(16)$ & $7.9(38)$ \\
\hline Mobile application & $17.3(9)$ & $12.5(3)$ & $10(18)$ & $14.6(31)$ & $7.7(2)$ & $16.9(29)$ & $12.2(60)$ \\
\hline Social media (Facebook and/or WhatsApp) & $13.5(7)$ & $8.3(2)$ & $18.9(34)$ & $19.8(42)$ & $23.1(6)$ & $15.7(27)$ & $19.1(94)$ \\
\hline Interactive voice response & 26.9 ab $(14)$ & $33.3^{\text {a }(8)}$ & $24.4^{\mathrm{b}}(44)$ & $29.3^{a b}(62)$ & $34.6^{\mathrm{a}}(9)$ & $23.3^{\mathrm{b}}(40)$ & $28.0 \mathrm{ab}(138)$ \\
\hline Major production obstacle during the pandemic $\left(\mathrm{X}^{2}=285.1, p<0.001\right)$ & 20 & 18 & 80 & 87 & 13 & 71 & 226 \\
\hline Farm management (extension services, farm monitor, and precision farming) & $0.0^{\mathrm{b}}(0)$ & $5.6^{\mathrm{b}}(1)$ & $18.8(15)^{a b}$ & $8.0(7)^{b}$ & $46.2(6)^{\mathrm{a}}$ & $14.1(10)^{b}$ & $12.3^{\mathrm{b}}(28)$ \\
\hline Shortage of labor & $25.0^{\mathrm{a}}(5)$ & $11.1^{\mathrm{b}}(2)$ & $23.7^{\text {a }}(19)$ & $13.8^{\mathrm{b}}(12)$ & $15.4^{\mathrm{b}}(2)$ & $18.3^{\mathrm{b}}(13)$ & $15.9^{\mathrm{b}}(36)$ \\
\hline Social distancing and movement restrictions & $50.0^{\mathrm{a}}(10)$ & $27.8^{\mathrm{b}}(5)$ & $13.7^{c}(11)$ & $32.2(28) \mathrm{ab}$ & $7.7^{c}(1)$ & $31.0^{\mathrm{ab}}(22)$ & $32.6^{\mathrm{ab}}(74)$ \\
\hline Product marketing & $5.0^{c}(1)$ & $27.8^{a}(5)$ & $17.5^{\mathrm{b}}(14)$ & $20.7^{\mathrm{ab}}(18)$ & $15.4^{\mathrm{b}}(2)$ & $12.7^{b}(9)$ & $13.2^{b}(30)$ \\
\hline Others & $5.0^{\mathrm{c}}(1)$ & $11.1^{\mathrm{ab}}(2)$ & $11.3^{\mathrm{ab}}(9)$ & $8.1^{\mathrm{b}}(7)$ & $0.0^{\mathrm{c}}(0)$ & $15.5^{\mathrm{ab}}(11)$ & $23.4^{\text {a }}(53)$ \\
\hline Main obstacle solved by using ICTs during the pandemic $\left(X^{2}=208.6, p<0.001\right)$ & 20 & 18 & 77 & 87 & 13 & 70 & 222 \\
\hline Farm management (extension services, farm monitor, and precision farming) & $20.0^{\mathrm{b}}(4)$ & $11.1^{\mathrm{b}}(2)$ & $31.2^{\mathrm{a}}(24)$ & $26.4^{\mathrm{ab}}(23)$ & $38.5^{\mathrm{a}}(5)$ & $28.6^{\mathrm{ab}}(20)$ & $23.4^{\mathrm{ab}}(52)$ \\
\hline Access production inputs & $25.0^{\mathrm{a}}(5)$ & $27.8^{\text {a }}(5)$ & $16.9^{\mathrm{b}}(13)$ & $10.3^{\mathrm{b}}(9)$ & $23.1^{\mathrm{ab}}(3)$ & $22.9^{\mathrm{ab}}(16)$ & $13.5^{\mathrm{b}}(30)$ \\
\hline Shortage of labor & $15.0^{\text {a }}(3)$ & $16.7^{\mathrm{a}}(3)$ & $15.6^{\mathrm{a}}(12)$ & $6.9^{\mathrm{b}}(6)$ & $15.4^{\mathrm{a}}(2)$ & $7.1^{\mathrm{b}}(5)$ & $9.0^{\mathrm{b}}(20)$ \\
\hline Social distancing and movement restrictions & $10.0(2)$ & $5.6(1)$ & $11.7(9)$ & $13.8(12)$ & $7.7(1)$ & $12.9(9)$ & $22.5(50)$ \\
\hline Product marketing & $25.0^{\mathrm{b}}(5)$ & $33.3^{\mathrm{ab}}(6)$ & $22.1(17)^{b}$ & $40.2^{\mathrm{a}}(35)$ & $7.7^{c}(1)$ & $24.3^{\mathrm{b}}(17)$ & $17.6^{\text {bc }}(39)$ \\
\hline Others & $5.0(1)$ & $5.6(1)$ & $2.6(2)$ & $2.3(2)$ & $7.7(1)$ & $4.3(3)$ & $14.0(31)$ \\
\hline Who do support ICTs in your country $\left(X^{2}=463.317, p<0.001\right)$ & 30 & 19 & 96 & 116 & 21 & 95 & 313 \\
\hline Authority and government & $23.3(7)$ & $31.6(6)$ & $26.1(25)$ & $31.9(37)$ & $38.1(8)$ & $24.2(23)$ & $29.7(93)$ \\
\hline International or local organizations & $26.7^{\mathrm{a}}(8)$ & $15.8^{\mathrm{b}}(3)$ & $29.2^{\mathrm{a}}(28)$ & $20.7^{\mathrm{ab}}(24)$ & $19.0^{\mathrm{ab}}(4)$ & $12.6(12)^{b}$ & $14.7^{\mathrm{b}}(46)$ \\
\hline Specific educational support programs & $13.3(4)$ & $5.3(1)$ & $16.7(16)$ & $14.7(17)$ & $14.3(3)$ & $22.1(21)$ & $19.2(60)$ \\
\hline Personal support & $26.7(8)$ & $26.3(5)$ & $19.8(19)$ & $21.6(25)$ & $9.5(2)$ & $31.6(30)$ & $22.0(69)$ \\
\hline No one & $10.0(3)$ & $21.1(4)$ & $8.3(8)$ & $11.2(13)$ & $19.0(4)$ & $9.5(9)$ & $14.4(45)$ \\
\hline
\end{tabular}

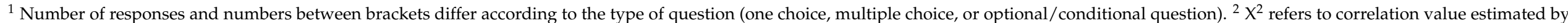

Chi-square test, $p$ refers to the significance of the correlation between two variables, and different superscript letters $(\mathrm{a}-\mathrm{c})$ indicate means with significant statistical differences at $p<0.05$. 


\section{Discussion}

\subsection{Knowledge of Agricultural ICTs before and after the COVID-19 Pandemic}

The results of the present cross-sectional study reveal that regardless of the emergence of the COVID-19 pandemic, most respondents working in the agricultural sector had sufficient knowledge of agricultural ICTs and their benefits. These results reflect the global direction toward using agricultural ICTs, the Internet, big data analysis, and other technological services in different economic and social sectors as an ongoing trend of globalization $[44,45]$. Farmers and other agricultural stakeholders now have a good awareness of the new agricultural ICTs and their beneficial returns on their farming systems. They believe that digitalization is a new path, which can fundamentally change the way of communication among suppliers, processors, manufacturers, retailers, and other stockholders involved in agro-livestock farming systems. This concept is supported by our findings, as approximately $50 \%$ of the respondents indicated that they used at least one of the agricultural ICTs as a routine application in their agribusinesses even before the emergence of the COVID-19 pandemic. The same conclusion can be made on the basis of the availability of agricultural ICTs and the ease of handling, as most respondents scored high values (very easy, easy, and intermediate) for these variables. However, the subgroup analyses of our data revealed the need to pay further attention to some categories to develop their skills toward agricultural ICT use and to improve the affordability of different agricultural ICTs for them. Stakeholders belonging to developing countries, small holders, and laborers expressed some difficulties in the use and availability of agricultural ICTs. These findings are in agreement with those of other previous studies that reported the importance of supporting vulnerable groups, specifically in developing countries (South Africa [26], Sub-Saharan Africa [27], and China [46]), and how such support can ensure the transformation and integration of digital technologies necessary for readiness and innovation process [46].

Interestingly, a high percentage of these categories revealed that they started to use agricultural ICTs after the emergence of the pandemic. Thus, the emergence of the pandemic has encouraged such categories to use agricultural ICTs to solve production obstacles and maintain their agribusinesses sustainability while maintaining social distancing instructions. In general, during the pandemic period, digital technologies have emerged as essential tools to disseminate and share information through various digital platforms and social media as solutions for social distancing measures [35,47].

Notably, a high percentage of the respondents, who had not previously used agricultural ICTs, shared that they did not use agricultural ICTs due to high prices, unaffordability, and/or their ignorance about these technologies. Increasing the investment in digitalization technologies can support the agricultural sector in developing countries and help smallscale farmers yield far-reaching benefits long after the pandemic has passed. However, it requires increasing efforts and strong partnerships among governments, businesses, and farmers, including a regulatory environment, to ensure that technologies remain affordable and accessible, either under normal or extreme conditions [48]. The transfer of agricultural ICT approaches must adopt flexible and adaptable strategies, which can be initiated by applying simple strategies, such as regular extension programs and on-farm trials [28].

The revolution of agricultural digitalization has led to the development of different ICTs with a wide range of applications, which can be applied along the agricultural supply chain to support the resilience and sustainability of all key elements of this chain. Currently, several innovative agricultural ICTs may be applied in the agricultural sector, including cloud computing/big data analysis tools, artificial intelligence, machine learning, digital communication technologies (mobile phones), digital platforms (e.g., ecommerce platforms, agro-advisory applications, and e-extension websites), precision agriculture technologies (sensors and wearable devices), advanced imaging technologies (satellite and drone imagery), and automated machinery and agricultural robots [9]. In this study, the most commonly used agricultural ICTs by the respondents, either before or after the emergence of the pandemic, were social media (Facebook and/or WhatsApp), online platforms and In- 
ternet services, mobile applications, and interactive voice response. In contrast, agricultural ICTs, including wearable and sensor technology and robotic vehicles, were less frequently used. Nevertheless, both were among the major technologies used in developed countries, specifically during the period of the pandemic emergence. These findings are consistent with those reported in similar studies [12,49]. For example, Madushanki et al. [49] indicated that $\mathrm{Wi}-\mathrm{Fi}$ and mobile technology are the most frequently used technologies by applicants involved in the agriculture and farming industries. Together, these results reflect the importance of the affordability, price, and ease of use of these technologies. Most technologies, which depend on mobile phones and Internet services, are easy to use and available at acceptable prices, thereby making them the common agricultural ICTs used in the agricultural sector. Today, most farmers have mobile phones and thus can easily receive targeted agricultural advice through simple texts or voice messages even without accessing the Internet. The use of such simple technologies has led to real advancements in the agricultural sector in many countries. For example, in Odisha, India, the Precision Agriculture for Development organization has delivered free agricultural advice to almost 800,000 farmers through their phones and to other farmers in Bangladesh, Ethiopia, India, Kenya, Pakistan, Rwanda, Uganda, and Zambia [48]. ICTs play an integrating role in research-extension-farmer linkage. Mobile and Internet-based technologies are not only limited to deliver agricultural extensions but also can help farmers and stakeholders access production inputs and follow consumer demand and product marketing [26].

\subsection{Impact of the COVID-19 Pandemic on the Agro-Livestock Production Systems and Consequences on Agricultural ICT Development}

Regarding the role and importance of the agricultural ICTs during the emergence of the COVID-19 pandemic, the spread of this pandemic is widely believed to have strongly impacted the agro-livestock production systems worldwide $[9,10,50]$. The agricultural key supply chains have been interrupted at different levels due to movement restrictions, lack of production inputs, market closure, shortage of agriculture labor, and constrained currency liquidity [8]. Thus, global supply chains in the agricultural and food industries have struggled to cope with panic buying, followed by forced changes in food consumption patterns and large declines in incomes [51]. Our cross-sectional study confirmed such production obstacles during the pandemic period, specifically social distancing, shortage of labor, and precision farming management. The subgroup analyses of our data revealed the presence of some specific production obstacles; for example, the respondents belonging to developed countries indicated that the shortage of labor was one of the specific production obstacles. It reflects how the pandemic has caused a great shortage of labor, which presents a real problem for developed countries relying on imported workforce and foreign migrated laborers [52]. In addition, the subgroup analyses suggested that product marketing was the main production obstacle that challenged those belonging to developing countries and small-scale agribusiness owners. These findings may reflect the negative impacts of the pandemic on the trade and purchasing empower, affecting the agribusiness sustainability of these vulnerable subcategories.

Interestingly, as inferred from the respondents' answers obtained in this global survey on agricultural ICTs conducted after the onset of the COVID-19 crisis, applying agricultural ICTs during the pandemic period has been found to be effective in solving production obstacles, including precision farm management, product marketing, and social distancing and movement restrictions. Many farmers, specifically those involved in livestock production systems, have imposed the repopulations of animals in their farms, discarding and killing animals due to weak consumer demands for animal products and surplus animal products [8]. Moreover, dairy farmers have to dump thousands of milk gallons, which conflicts with the food security concept and contributes to global food insecurity crisis [53-55].

Finally, our results indicate for the first time after the onset of the COVID-19 crisis that there is an international/global trend toward the digitalization of the agricultural sector, as most respondents belonging to different geographic regions either in developing 
or developed countries revealed that the agricultural ICTs are financially supported by their authorities and governments. However, more support is still required since a similar percentage of the respondents revealed that they personally support the agricultural ICTs that they use. Governments need to take vigorous steps to facilitate agricultural ICTs use by different stakeholders of the agricultural sector, emphasizing increasing knowledge of the benefits of such technologies and improving stakeholder skills to use all available agricultural ICTs including those of high technology such as robotics and drones. This would consequently contribute to empowering the role of the agricultural sector to cope with increasing food demands and to sustain the resilience of the food chain in face of unexpected crises such that has raised following the emergence of the COVID-19 pandemic [56].

\section{Conclusions}

According to the first hypothesis (socio-economic factors, availability, and affordability can affect the dissemination of agricultural ICTs) proposed in this study, our results reveal that the wide dissemination of agricultural ICTs among farmers/stakeholders still needs additional support to improve applicants' handling skills and awareness of agricultural ICTs; specifically, a high proportion of the respondents revealed their acceptance of such technologies and believed in the importance of these technologies in improving the outputs of their agribusinesses. Our results also suggest that support from the authorities and international/national agricultural organizations is required to improve the digital-related infrastructure for facilitating access to different agricultural ICTs, focusing on the most available technologies for all users, such as Internet platforms and mobile-related applications.

According to the second and third hypotheses (agricultural ICTs have positive roles in agro-livestock farming system sustainability during normal and critical times), the benefits of agricultural ICTs were confirmed in our study as many of the respondents shared that the use of agricultural ICTs was a routine measure even before the emergence of the pandemic. Moreover, the application of agricultural ICTs during the pandemic solved many production obstacles and facilitated farm monitoring and social communication.

In addition, the subgroup analyses of our data highlight the importance of supporting the use and increasing the availability and awareness of agricultural ICTs at least for some vulnerable groups of people, such as those belonging to developing countries, laborers, and small-scale agribusiness holders.

These findings are consistent with the existing studies that empirically support the positive role of agricultural ICTs in developing and sustaining the resilience of agro-livestock farming systems [38,57-59]. However, to the best of the authors' knowledge, no studies have assessed how the emergence of the COVID-19 pandemic changed the dynamics of the digitalization of the agricultural sector worldwide, considering the social and economic statuses of the participants. In light of our findings, we recommend researchers and policymakers to innovate robust strategies to monitor and solve any unexpected crises, which can disrupt the livelihoods and food security of humans.

Overall, the summary of this global survey conducted after the emergence of the pandemic highlights the urgent need to expand the use of new agricultural ICTs on different production and social scales to meet the growing demand for food production worldwide. This unique study also emphasizes the need for an improved use of agricultural ICTs to ensure the resilience and sustainability of agro-livestock farming systems, specifically under unexpected and extreme conditions, such as sanitary crises, which are likely to be unfortunately numerous.

Future studies should examine other factors that can affect the dissemination of agricultural ICTs among farmers/stakeholders, such as sex, age, and education level, including the type of agricultural activity (crop, livestock, or integrated production systems), as these factors are not fully explored in our study. In addition, investigating the roles of authorities and policymakers in supporting the use of agricultural ICTs, specifically in developing countries, may help induce a real progress in the agro-livestock production system in the near future. Finally, mentioning that our study was conducted at a critical and short 
time that encompasses the COVID-19 pandemic emergence period is important. Thus, other studies, which can examine the hypothesis about the effectiveness of agricultural ICTs to maintain the sustainability of the agricultural sector in the long run and in normal conditions, would be interesting.

Supplementary Materials: The following are available online at https:/ /www.mdpi.com/article/ 10.3390/su13126521/s1, Figure S1: Multi-correspondence analysis of the data, showing possible relationships between different categories. (Questions labeled A, C, D, O, P, H, and J were used as supplementary data).

Author Contributions: N.M.H.: designed the survey and wrote the first draft. N.M.H., E.M.H., J.-F.H., A.G.-B., Y.A.A., K.A.A.: translated the questionnaire and circulated the questionnaire. N.M.H., E.M.H., J.-F.H., A.G.-B., Y.A.A., F.A.A.: collected data. N.M.H., J.-F.H.: analyzed the data. N.M.H., J.-F.H., A.G.-B.: reviewed the article and prepared final version of the manuscript. All authors have read and agreed to the published version of the manuscript.

Funding: This research received no external funding.

Institutional Review Board Statement: Not applicable.

Informed Consent Statement: Not applicable.

Data Availability Statement: The data presented in this study are available on request from the corresponding author. The data are not publicly available due to privacy.

Conflicts of Interest: The authors declare no conflict of interest.

\section{References}

1. Food and Agriculture Organization of the United Nations (FAO). World Food and Agriculture-Statistical Yearbook 2020; FAO: Rome, Italy, 2020. Available online: http:/ / www.fao.org/3/cb1329en/online/cb1329en.html (accessed on 3 November 2020).

2. Lenzen, M.; Li, M.; Malik, A.; Pomponi, F.; Sun, Y.Y.; Wiedmann, T.; Faturay, F.; Fry, J.; Gallego, B.; Geschke, A.; et al. Global socio-economic losses and environmental gains from the coronavirus pandemic. PLoS ONE 2020, 15, e0235654. [CrossRef]

3. United Nations (UN) World Population Projected to Reach 9.7 Billion by 2050. Available online: https://www.un.org/ development/desa/en/news/population/2015-report.html (accessed on 3 November 2020).

4. Emadi, M.H.; Rahmanian, M. Commentary on Challenges to Taking a Food Systems Approach within the Food and Agriculture Organization (FAO). In Food Security and Land Use Change under Conditions of Climatic Variability; Springer: Berlin/Heidelberg, Germany, 2020; pp. 19-31.

5. Jones, B.A.; Grace, D.; Kock, R.; Alonso, S.; Rushton, J.; Said, M.Y.; McKeever, D.; Mutua, F.; Young, J.; McDermott, J.; et al. Zoonosis emergence linked to agricultural intensification and environmental change. Proc. Natl. Acad. Sci. USA 2013, 110, 8399-8404. [CrossRef]

6. Hashem, N.M.; Abdelnour, S.A.; Alhimaidi, A.R.; Swelum, A.A. Potential impacts of COVID-19 on Reproductive Health: Scientific Findings and Social Dimension. Saudi J. Biol. Sci. 2020. [CrossRef]

7. Hafez, H.M.; Attia, Y.A. Challenges to the Poultry Industry: Current Perspectives and Strategic Future after the COVID-19 Outbreak. Front. Vet. Sci. 2020, 7. [CrossRef]

8. Hashem, N.M.; González-Bulnes, A.; Rodriguez-Morales, A.J. Animal Welfare and Livestock Supply Chain Sustainability under the COVID-19 Outbreak: An Overview. Front. Vet. Sci. 2020, 7, 679. [CrossRef] [PubMed]

9. Hussain, S.; Hussain, A.; Ho, J.; Sparagano, O.A.E.; Zia, U.-R. Economic and social impacts of COVID-19 on animal welfare and dairy husbandry in Central Punjab, Pakistan. Front. Vet. Sci. 2020, 23, 589971. [CrossRef] [PubMed]

10. Al-Khalaifah, H.; Al-Nasser, A.; Abdulmalek, N.; Al-Mansour, H.; Ahmed, A.; Ragheb, G. Impact of SARS-Con-V2 on the Poultry Industry in Kuwait: A Case Study. Front. Vet. Sci. 2020, 7, 656. [CrossRef] [PubMed]

11. Wolfert, S.; Ge, L.; Verdouw, C.; Bogaardt, M.J. Big Data in Smart Farming-A review. Agric. Syst. 2017, 153, 69-80. [CrossRef]

12. Fielke, S.; Taylor, B.; Jakku, E. Digitalisation of agricultural knowledge and advice networks: A state-of-the-art review. Agric. Syst. 2020, 180, 102763. [CrossRef]

13. Frankelius, P.; Norrman, C.; Johansen, K. Agricultural innovation and the role of institutions: Lessons from the game of drones. J. Agric. Environ. Ethics 2019, 32, 681-707. [CrossRef]

14. Trendov, N.M.; Varas, S.; Zeng, M. Digital Technologies in Agriculture and Rural Areas; FAO: Rome, Italy, $2019 ;$ p. 26.

15. Bacco, M.; Barsocchi, P.; Ferro, E.; Gotta, A.; Ruggeri, M. The Digitisation of Agriculture: A Survey of Research Activities on Smart Farming. Array 2019, 3-4, 100009. [CrossRef]

16. Aleksandrova, M. IoT in Agriculture: Five Technology Uses for Smart Farming and Challenges to Consider. IoT News 2018. Available online: https:/ / dzone.com/articles/iot-in-agriculture-five-technology-uses-for-smart (accessed on 3 November 2020). 
17. Market Research Report. Smart Agriculture Market Share, Size, Trends, Industry Analysis Report, Report code PM1404. POLARIS Mark. Res. 2019. Available online: https://www.polarismarketresearch.com/industry-analysis/smart-agriculture-market (accessed on 3 November 2020).

18. Smart Agriculture Market. Smart Agriculture Market by Agriculture Type, Report Code SE 4343. Mark. Mark. 2020. Available online: https: / / www.industryarc.com/Report/15370/smart-agriculture-market.html (accessed on 3 November 2020).

19. Hocquette, J.; Capel, C.; David, V.; Guemene, D.; Bidanel, J.; Ponsart, C.; GastineL, P.; Le Bail, P.; Monget, P.; Mormede, P. Objectives and applications of phenotyping network set-up for livestock. Anim. Sci. J. 2012, 83, 517-528. [CrossRef] [PubMed]

20. Amjath-Babu, T.S.; Krupnik, T.J.; Thilsted, S.H.; McDonald, A.J. Key indicators for monitoring food system disruptions caused by the COVID-19 pandemic: Insights from Bangladesh towards effective response. Food Secur. 2020, 12, 761-768. [CrossRef] [PubMed]

21. Food and Agriculture Organization of the United Nations (FAO). Transforming Agriculture in AFRICA through Digitalization, New Webinar Series; FAO: Rome, Italy, 2020. Available online: http://www.fao.org/support-to-investment/news/detail/en/c/129424 $3 /$ (accessed on 3 November 2020).

22. Markets and Markets. COVID-19 Impact on Digital Agriculture Market. Available online: https://www.marketsandmarkets. com/Market-Reports / covid-19-impact-on-digital-agriculture-market-222616344.html (accessed on 4 February 2021).

23. Schukat, S.; Heise, H. Smart Products in Livestock Farming-An Empirical Study on the Attitudes of German Farmers. Animals 2021, 11, 1055. [CrossRef]

24. Arese, L.; Okeleke, T. Market size and opportunity in digitising payments in agricultural value chains. GSMA Intell. 2016, 46. Available online: https: / / data.gsmaintelligence.com/api-web/v2/research-file-download?id=18809386\&file=market-size-andopportunity-in-digitising-payments-in-agricultural-value-chains-1482140000731.pdf (accessed on 4 February 2021).

25. Lowenberg-deboer, J.; Erickson, B. Setting the Record Straight on Precision Agriculture Adoption. Agron. J. 2019, 111, 1552-1569. [CrossRef]

26. Nwafor, C.U.; Ogundeji, A.A.; van der Westhuizen, C. Adoption of ICT-based information sources and market participation among smallholder livestock farmers in South Africa. Agriculture 2020, 10, 44. [CrossRef]

27. Gwaka, L.; Dubihlela, J. The resilience of smallholder livestock farmers in sub-saharan africa and the risks imbedded in rural livestock systems. Agriculture 2020, 10, 270. [CrossRef]

28. Dhehibi, B.; Rudiger, U.; Moyo, H.P.; Dhraief, M.Z. Agricultural technology transfer preferences of smallholder farmers in Tunisia's arid regions. Sustainability 2020, 12, 421. [CrossRef]

29. Nakasone, E.; Torero, M.; Minten, B. The Power of Information: The ICT Revolution in Agricultural Development. Annu. Rev. Resour. Econ. 2014, 6, 533-550. [CrossRef]

30. Carbonell, I.M. The ethics of big data in big agriculture. Internet Policy Rev. 2016, 5, 1-13. [CrossRef]

31. Silvestri, S.; Richard, M.; Edward, B.; Dharmesh, G.; Dannie, R. Going digital in agriculture: How radio and SMS can scale-up smallholder participation in legume-based sustainable agricultural intensification practices and technologies in Tanzania. Int. J. Agric. Sustain. 2020, 1-12. [CrossRef]

32. Goldfarb, A.; Tucker, C. Digital Economics; NBER Working Paper Series; 2017. Available online: https://www.nber.org/papers/ w23684 (accessed on 10 January 2021).

33. Casaburi, L.; Kremer, M.; Mullainathan, S.; Ramrattan, R. Harnessing ICT to Increase Agricultural Production: Evidence from Kenya. Harvard University, IPA and J-PAL. 2014. Available online: https:/ / www.gov.uk/research-for-development-outputs / harnessing-ict-to-increase-agricultural-production (accessed on 10 January 2021).

34. Gregorioa, G.B.; Ancog, R.C. Assessing the impact of the covid-19 pandemic on agricultural production in Southeast Asia: Toward transformative change in agricultural food systems. Asian J. Agric. Dev. 2020, 17, 1-13. [CrossRef]

35. Singh, L.; Singh, A.K.; Kumar, S. Impact of COVID-19 on Agriculture and Allied Sectors. J. Community Mobilization Sustain. Dev. 2020, 15, 8-16.

36. Hart, C.E.; Hayes, D.J.; Jacobs, K.L.; Schulz, L.L.; Crespi, J.M. The impact of COVID-19 on iowa's corn, soybean, ethanol, pork, and beef Sectors. Cent. Agric. Rural Dev. 2020, 294-6336. Available online: https://lib.dr.iastate.edu/card_policybriefs/30/ (accessed on 10 January 2021).

37. Food and Agriculture Organization of the United Nations (FAO). Enabling Agricultural Innovation Systems to Promote Appropriate Technologies and Practices for Farmers, Rural Youth and Women during COVID-19; FAO: Rome, Italy, 2020.

38. El Bilali, H.; Allahyari, M.S. Transition towards sustainability in agriculture and food systems: Role of information and communication technologies. Inf. Process. Agric. 2018, 5, 456-464. [CrossRef]

39. Emeana, E.M.; Trenchard, L.; Dehnen-Schmutz, K. The revolution of mobile phone-enabled services for agricultural development (m-Agri Services) in Africa: The challenges for sustainability. Sustainability 2020, 12, 485. [CrossRef]

40. Liu, J.; Hocquette, É.; Ellies-Oury, M.-P.; Chriki, S.; Hocquette, J.-F. Chinese Consumers' Attitudes and Potential Acceptance toward Artificial Meat. Foods 2021, 10, 353. [CrossRef]

41. Gastwirth, J.L.; Gel, Y.R.; Miao, W. The Impact of Levene's Test of Equality of Variances on Statistical Theory and Practice. Stat. Sci. 2009, 24, 343-360. [CrossRef]

42. United Nations (UN). World Economic Situation and Prospects; United Nations (UN): 2021 United Nations Publication Sales No. E.21.II.C.1. Available online: https://www.un.org/development/desa/dpad/wp-content/uploads/sites/45/WESP2021_ FullReport.pdf (accessed on 3 November 2020). 
43. Food and Agriculture Organization of the United Nations (FAO). Guidelines for Development of a Classification System Related to Farm Typology; FAO: Rome, Italy, 2018; p. 224. Available online: http://www.fao.org/food-agriculture-statistics/resources/ publications/guidelines-and-handbooks/en/ (accessed on 3 November 2020).

44. Eastwood, C.; Klerkx, L.; Ayre, M.; Rue, B. Dela Managing Socio-Ethical Challenges in the Development of Smart Farming: From a Fragmented to a Comprehensive Approach for Responsible Research and Innovation. J. Agric. Environ. Ethics 2019, 32, 741-768. [CrossRef]

45. Carolan, M. Publicising Food: Big Data. Precis. Tech. Addit. 2016. [CrossRef]

46. Zeng, Y.; Ji, F.; Wa, L.; Guo, H. E-commerce in agri-food sector: A systematic literature review. Int. Food Agribus. Manag. Rev. 2017, 20, 439-460. [CrossRef]

47. Meena, H.; Singh, Y. Importance of information and communication technology tools among livestock farmers: A review Review article Importance of information and communication technology tools among livestock farmers: A review. Sci. J. Pure Appl. Sci. 2013. [CrossRef]

48. Kremer, M. Grow Back Better? Here's How Digital Agriculture Could Revolutionise Rural Communities Affected by COVID-19. Available online: https:/ / www.weforum.org/agenda/2020/07/digital-agriculture-technology (accessed on 3 November 2020).

49. Madushanki, A.A.R.; Halgamuge, M.N.; Wirasagoda, W.A.H.S.; Syed, A. Adoption of the Internet of Things (IoT) in agriculture and smart farming towards urban greening: A review. Int. J. Adv. Comput. Sci. Appl. 2019, 10, 11-28. [CrossRef]

50. Galanakis, C.M. The Food Systems in the Era of the Coronavirus (COVID-19) Pandemic Crisis. Foods 2020, 9, 523. [CrossRef]

51. Krpálková, L.; Burns, S.; O’Mahony, N.; Carvalho, A.; Campbell, S.; Velasco-Hernandez, G.; Walsh, J. Interactive comparison tool for management of reproduction based on pregnancy rate. In Proceedings of the Precision Livestock Farming 2019-Papers Presented at the 9th European Conference on Precision Livestock Farming, Cork, Ireland, 26-29 August 2019; pp. 370-378.

52. EURACITY Germany to Relax Coronavirus Border Controls for Farm Workers. Available online: https://www.euractiv. $\mathrm{com} /$ section/agriculture-food/news/germany-to-relax-coronavirus-border-controls-for-farm-workers/ (accessed on 4 November 2020).

53. Aborode, A.T.; Ogunsola, S.O.; Adeyemo, A.O. A Crisis within a Crisis: COVID-19 and Hunger in African Children. Am. J. Trop. Med. Hyg. 2020, 2018, 2019-2021. [CrossRef]

54. Food and Agriculture Organization of the United Nations (FAO). Digital Technology Applications in COVID-19 Response Plans. 2020. Available online: http:/ / www.fao.org/land-water/overview/covid19/digital/ru/ (accessed on 14 December 2020).

55. Food and Agriculture Organization of the United Nations (FAO). COVID-19 and the Risk to Food Supply Chain: How to Respond? Policy Support and Governance. 2020. Available online: http:/ / www.fao.org/3/ca8388en/CA8388EN.pdf (accessed on 15 December 2020).

56. Timilsina, B.; Adhikari, N.; Kafle, S.; Paudel, S.; Poudel, S.; Gautam, D. Addressing Impact of COVID-19 Post Pandemic on Farming and Agricultural Deeds. Asian J. Adv. Res. Rep. 2020, 11, 28-35. [CrossRef]

57. Bucci, G.; Bentivoglio, D.; Finco, A. Factors affecting ict adoption in agriculture: A case study in Italy. Qual. Access Success 2019, 20, 122-129.

58. Ouweltjes, W.; De Haas, Y.; Kamphuis, C. At-market sensor technologies to develop proxies for resilience and efficiency in dairy cows. In Proceedings of the Precision Livestock Farming 2019-Papers Presented at the 9th European Conference on Precision Livestock Farming, 2019; pp. 246-253. Available online: https:/ / research.wur.nl/en/publications/at-market-sensortechnologies-to-develop-proxies-for-resilience-a-2 (accessed on 4 November 2020).

59. Ren, G.; Lin, T.; Ying, Y.; Chowdhary, G.; Ting, K.C. Agricultural robotics research applicable to poultry production: A review. Comput. Electron. Agric. 2020, 169. [CrossRef] 